\title{
Plant Defense Stimulation by Natural Isolates of Bacillus Depends on Efficient Surfactin Production
}

\author{
Hélène Cawoy, ${ }^{1}$ Martin Mariutto, ${ }^{2}$ Guillaume Henry, ${ }^{1}$ Christophe Fisher, ${ }^{3}$ Natallia Vasilyeva, ${ }^{2}$ Philippe \\ Thonart, ${ }^{1}$ Jacques Dommes, ${ }^{2}$ and Marc Ongena ${ }^{1}$ \\ ${ }^{1}$ Walloon Center of Industrial Biology, University of Liège/Gembloux Agro-Bio Tech, Passage des Déportés, 2, Gembloux, \\ Belgium; ${ }^{2}$ Laboratory of Plant Molecular Biology and Biotechnology, Faculty of Sciences, Department of Life Sciences, \\ University of Liège, Boulevard du Rectorat, 27, Liège, Belgium; ${ }^{3}$ Laboratory of Analytical Chemistry, University of Liège/ \\ Gembloux Agro-Bio Tech, Passage des Déportés, 2, Gembloux, Belgium
}

Submitted 5 September 2013. Accepted 11 October 2013.

\begin{abstract}
Some plant-associated Bacillus strains produce induced systemic resistance (ISR) in the host, which contributes to their protective effect against phytopathogens. Little is known about the variety of elicitors responsible for ISR that are produced by Bacillus strains. Working with a particular strain, we have previously identified the surfactin lipopeptide as a main compound stimulating plant immunerelated responses. However, with the perspective of developing Bacillus strains as biocontrol agents, it is important to establish whether a central role of surfactin is generally true for isolates belonging to the $B$. subtilis/amyloliquefaciens complex. To that end, we set up a comparative study involving a range of natural strains. Their secretomes were first tested for triggering early defense events in cultured tobacco cells. Six isolates with contrasting activities were further evaluated for ISR in plants, based both on macroscopic disease reduction and on stimulation of the oxylipin pathway as defense mechanism. A strong correlation was found between defense-inducing activity and the amount of surfactin produced by the isolates. These results support the idea of a widespread role for surfactin as a nonvolatile elicitor formed by B. subtilis/amyloliquefaciens, and screening for strong surfactin producers among strains naturally secreting multiple antibiotics could be an efficient approach to select good candidates as biopesticides.
\end{abstract}

Plant roots constantly release a variety of organic compounds that diffuse in the few millimeters of the surrounding soil layer, thereby creating a niche favorable for development of very diverse microbial populations. Among these communities inhabiting the so-called rhizosphere, some bacteria (termed plant growth-promoting rhizobacteria [PGPR]) may provide beneficial effects to the host plant by directly promoting its growth or by protecting it against phytopathogens (Lugtenberg and Kamilova 2009). Commercialized as biopesticide products, these bacteria constitute potent new tools for sustainable agriculture (Choudhary and Johri 2009).

H. Cawoy and M. Mariutto contributed equally to this work.

Corresponding author: M. Ongena; E-mail: Marc.Ongena@ulg.ac.be; Telephone: +32 81622305; Fax: +32 81614222.

* The $\boldsymbol{e}$-Xtra logo stands for "electronic extra" and indicates that four supplementary figures are published online.

(C) 2014 The American Phytopathological Society
PGPR may act through several mechanisms for disease protection, including competition with pathogens for ecological niche or substrate in the rhizosphere and production of antibiotics with direct inhibitory activity on infectious agents (Bhattacharyya and Jha 2012). This direct antagonism of pathogen growth is viewed as the most powerful and best characterized mechanism. Soil Bacillus and Paenibacillus species (such as Paenibacillus polymyxa) actually devote from 4 to $8 \%$ of their genome to antibiotic synthesis and, therefore, display the potential to produce a vast array of structurally diverse antimicrobial compounds (Chen et al. 2009; Rückert et al. 2011; Stein 2005). Certain isolates of Bacillus and Paenibacillus species are among the most efficient microbial biocontrol agents (McSpadden Gardener 2004), and some strains have been developed to reach the market level.

A third mechanism through which rhizobacteria may inhibit phytopathogens is the strengthening of the host plant's defensive potential via stimulation of its immune machinery. Historically, this last mechanism was first discovered in response to pathogens. Upon perception of specific compounds secreted or harbored by the attacker (pathogen associated molecular patterns [PAMPS]), plants can actually evolve an array of defense mechanisms to counteract infection. This immune response is first manifested locally in the pest-colonized organ but may also occur systemically in the noninfected tissues via molecular signaling, leading to the systemic acquired resistance phenomenon (Durrant and Dong 2004; Luna et al. 2012; Shah 2009; van den Burg and Takken 2009). Interestingly, certain nonpathogenic rhizobacteria can also trigger a phenotypically similar immune response called PGPR-ISR (induced systemic resistance). A variety of elicitors are emitted by PGPR and are perceived by plant cells to initiate the ISR phenomenon. The number of these molecules that are known has globally increased in recent decades (De Vleesschauwer and Höfte 2009; Jankiewicz and Kołtonowicz 2012; Van Loon 2007) but remains quite limited in the case of gram-positive species. For Bacillus strains, volatile compounds such as 2,3-butandiol and acetoin, 2-aminobenzoic acid and lipopeptides (LP) are the sole metabolites that were identified as elicitors of plant defense responses to date (Henry et al. 2012; Jourdan et al. 2009; Ongena and Jacques 2008; Ryu et al. 2004; Yang et al. 2011).

The main LP synthesized by B. subtilis/amyloliquefaciens belong to the surfactin, iturin, and fengycin families. They vary in the type, number, and sequence of amino acid residues as well as in the nature of the peptide cyclization. Moreover, within each family, several homologues differing in the length and isomery of the fatty acid chain are usually coproduced by 
Bacillus strains (Ongena and Jacques 2008). These compounds have been demonstrated to play a crucial role in the biocontrol potential of numerous isolates (Ongena and Jacques 2008; Raaijmakers et al. 2010). LP may contribute to the ability of the bacterium to efficiently colonize surfaces of plant roots. They also display strong and specific antibiotic activities allowing direct antagonism against various pathogens. In addition, the potential of surfactin as plant resistance inducer has been demonstrated in our laboratory, either using overproducing mutants from a specific strain or by applying the pure compound (Jourdan et al. 2009; Ongena et al. 2007). Disease reduction induced by surfactin was associated with defense-related metabolic changes occurring either very early after perception, such as ion fluxes across the plasma membrane and oxidative burst generating reactive oxygen species (ROS), or expressed later as defense mechanisms sensu stricto that limit or inhibit further pathogen penetration into the host plant tissues (Henry et al. 2011; Jourdan et al. 2009; Ongena et al. 2007).

The huge potential of $B$. amyloliquefaciens/subtilis species to trigger ISR does not seem to reflect the very limited number of their metabolites identified so far as elicitors. Other molecules than those cited above could, thus, putatively act as stimulators of systemic resistance. Alternatively, the ISR potential of Bacillus strains may rely on the potential to secrete or harbor the same specific compound. In this context, the present work was initiated to evaluate the importance of surfactin for the elicitation of ISR by various Bacillus strains. As a basis for our bottom-up strategy, we selected a range of rhizosphere isolates based on of their low, intermediate, or high production of the LP under specific in vitro conditions. Their corresponding supernatant extracts were tested for the capacity to stimulate the oxidative burst (considered a marker of early defense response) in cultured tobacco cells and ISR in tobacco plants. A limited number of strains were further evaluated for their potential to trigger systemic resistance in tomato, and disease reduction observed macroscopically was associated with the expression of molecular defense mechanisms stimulated in the host plant. Differential disease reduction by the various strains in tomato was also interpreted in light of their rhizosphere fitness and in situ surfactin production.

\section{RESULTS}

\section{Induction of oxidative burst in tobacco cells.}

For this comparative study, we selected seventeen Bacillus strains isolated from the phytosphere and belonging to the species B. subtilis, B. amyloliquefaciens, B. pumilus, and $P$. polymyxa. These isolates were selected according to their different LP signatures, which were determined in agitated cultures, using a rich medium optimized for production of these compounds. Some isolates did not produce any LP; others produced two or all three families of LP, including iturins (or their bacillomycintype variants), fengycins, and surfactins, in specific relative proportions. This is illustrated in Figure 1 presenting high-performance liquid chromatography mass spectrometry (HPLC-MS) analyses of culture extract for six representative strains selected from strains included in this work. Among strains producing all three famillies of LP, some isolates, such as B. amyloliquefaciens S499, produced mainly surfactins and only low levels of other LP, while others efficiently secreted iturins (98S) or both iturins and fengycins (QST713, FZB42). For purposes of clarity, the terms surfactin, iturin, and fengycin will be used throughout the following text in the singular form to designate the groups of surfactin, iturin, and fengycin homologues with different fatty acid chains. Some strains (such as BNO1) did not produce any LP of these families, and their chromatograms show only background noise. For the purpose of this study, Bacillus iso- lates were grown under pellicle- or biofilm-forming conditions in order to get closer to the natural context. Indeed, rhizobacterial microcolonies developing on plant roots are considered to be biofilm-related structures and not planktonic individual cells (Bais et al. 2004; Ramey et al. 2004). Surfactin production under these conditions was also quantified by LC-MS analysis, and results are presented in Figure 2A.

In a first approach, we wanted to establish a possible correlation between surfactin concentrations in crude supernatants of the various strains with the potential of these extracts to induce some early defense responses in plant cells. To that end, equal volumes of the various supernatants were tested on cultured tobacco cells for their oxidative burst-inducing activity. This phenomenon, measured through a luminol-based chemiluminescence assay, has been previously identified as a readily quantifiable marker of defense response following surfactin elicitation (Henry et al. 2011; Jourdan et al. 2009). As shown in Figure 2B, only supernatants obtained from cultures of strains B. amyloliquefaciens S499, B. subtilis 98S, B. subtilis 76, and $B$. subtilis 23 significantly stimulated ROS accumulation in tobacco cells compared with water control. For these samples, treatments corresponded to final surfactin concentrations in contact with the tobacco cells of 13.8, 9.5, 11.6, and $7.4 \mu \mathrm{M}$, respectively. It has previously been shown that surfactin is effective at triggering a consistent oxidative burst response in tobacco cells in the specific 5- to $20-\mu \mathrm{M}$ range of concentrations (Jourdan et al. 2009). These data, thus, provided a first indication about the importance of the LP for triggering early defense events, since supernatant samples prepared from the other strains, which did not reach the threshold in surfactin concentration, were also not active at inducing oxidative burst. Moreover, the amplitude of oxidative burst response observed for the four supernatant samples was in the same range as observed by treating tobacco cells with $10 \mu \mathrm{M}$ pure surfactin (Jourdan et al. 2009). In support of the dose-response relationship observed, a linear correlation could be established between surfactin concentration in the sample applied to tobacco cells and the $\mathrm{H}_{2} \mathrm{O}_{2}$ production level triggered in plant cells $\left(\mathrm{R}^{2}=\right.$ 0.9515) (Supplementary Fig. 1).

In a second experiment, the four active culture supernatants were diluted in order to achieve a $10-\mu \mathrm{M}$ surfactin concentration on tobacco cells. They were further serially diluted to 0.2 $\mu \mathrm{M}$ on plant cells and were tested for ROS stimulation activity in comparison with the effect of the purified LP used at the same concentrations. Statistical comparison was conducted between several surfactin concentrations for the same strain. All concentrations except $0.2 \mu \mathrm{M}$ triggered a significant response in tobacco cells compared with the response to a water control. For all strains, the highest concentration $(10 \mu \mathrm{M})$ significantly triggered the strongest $\mathrm{H}_{2} \mathrm{O}_{2}$ production. Concentrations of 5 , 2 , and $1 \mu \mathrm{M}$ caused an intermediate response between that of $10 \mu \mathrm{M}$ and the water control. Such asymptotic decrease in activity with increasing dilutions corresponded well to the one observed upon treatment with pure surfactin (Fig. 3). The presence of another ROS-eliciting molecule that would have been active in a different concentration range was thus unlikely.

In additional assays, we have fractioned crude cell-free extracts on $\mathrm{C} 18$ cartridges, in order to separate surfactin from less hydrophobic compounds present in the four active supernatants. Adsorbed material was step-wise eluted with increasing concentrations of methanol $(0,20,40,60$, and $100 \%$ in water), and each fraction was tested for its ability to elicit an oxidative burst response. In all cases, only fractions eluted with pure methanol and containing surfactin triggered a response of tobacco cells (data no shown). This did not allow ruling out the possibility of another very hydrophobic molecule with a similar dose-response relationship, but collectively, 


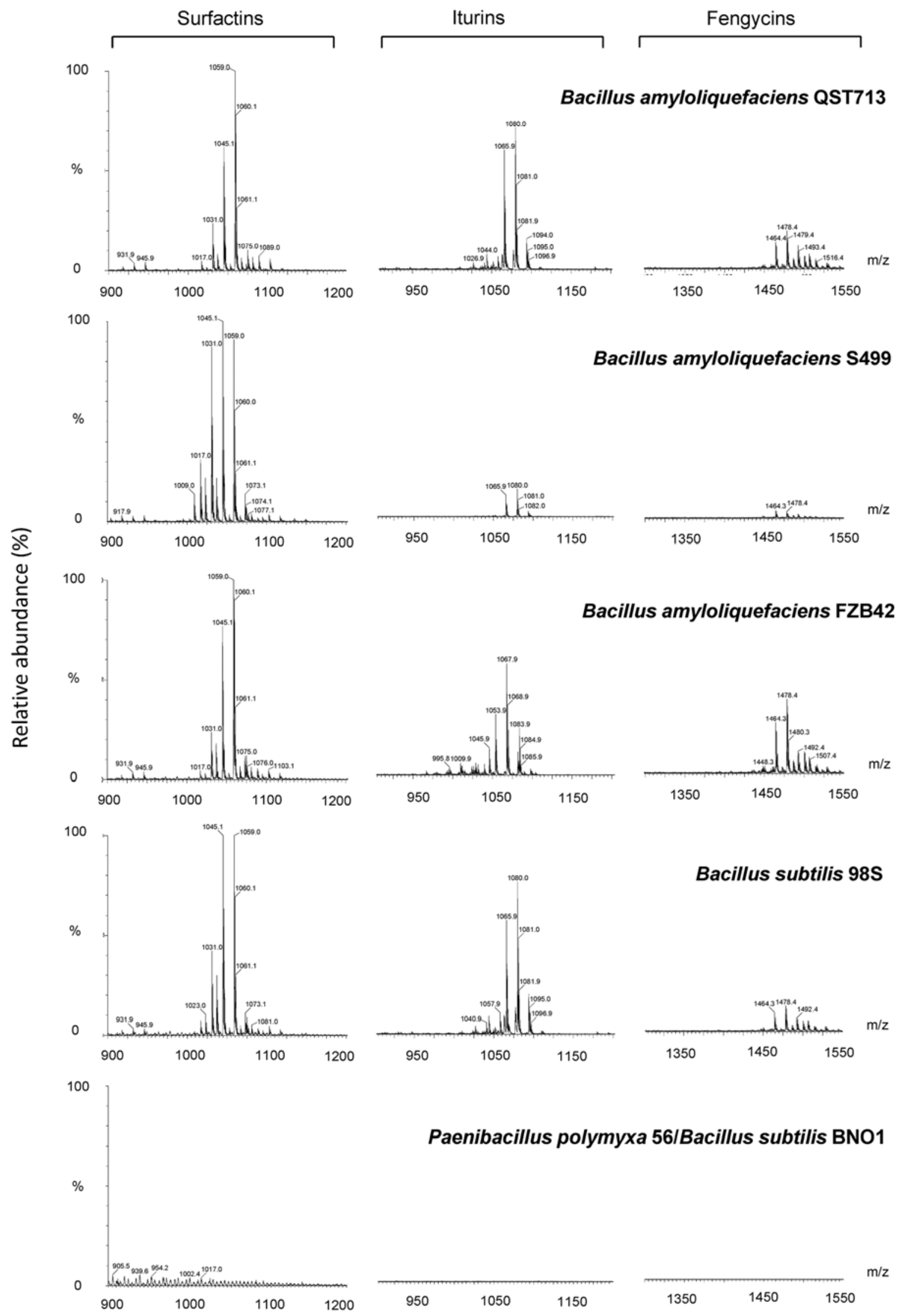

Fig. 1. Liquid chromatographic-electrospray mass spectrometry(MS) profiling of lipopeptides secreted by some of the isolates used in this work after cultivation under optimized conditions. For each lipopeptide family, several peaks are detected that correspond to the various co-produced homologues differing in the length and isomery of the fatty acid tail. Labeled ions mostly correspond to the $[\mathrm{M}+\mathrm{Na}]^{+}$form of the compounds. For each strain, $y$ axes in the mass spectra for surfactins, iturins, and fengycins represent total ion current values (relative abundance) and were linked at the same scale to allow comparison of the relative intensities of the ions correponding to the three lipopeptide (LP) families based on the peak area/height ratio. Data were obtained from analysis of extracts prepared from one culture but similar MS spectra and LP profiles were obtained in two repeats. 
the data obtained with cultured cells supported the hypothesis that surfactin is the only elicitor contained in all the supernatants tested.

\section{Induced systemic resistance in tobacco plants.}

Statistical analysis of data in Figure 2A indicated a clear and statistically significant segregation between producers and nonproducers of surfactin. Among producers, there is also some tendency to differentiate strains between medium and strong producers, although this is not statistically significant for most strains. Nevertheless, supernatant extracts from six strains were selected, on the basis of this categorization, to fur- ther test their potential to induce systemic resistance in tobacco plants, namely, B. amyloliquefaciens $\mathrm{S} 499$ and B. subtilis $98 \mathrm{~S}$ as strong producers of surfactin, $B$. amyloliquefaciens FZB42 and $B$. amyloliquefaciens QST713 as intermediate producers, and $P$. polymyxa 56 and $B$. subtilis $\mathrm{BNO1}$ as nonproducers (Fig. 2A).

In these assays, the extract tested for ISR-inducing activity and the pathogen were applied on different tissues to avoid direct antagonistic effects. Five-week-old plants cultivated in hydroponic conditions were thus treated at the root level with equal volumes of the corresponding supernatant extracts and were infected $48 \mathrm{~h}$ later, on detached sixth and seventh leaves
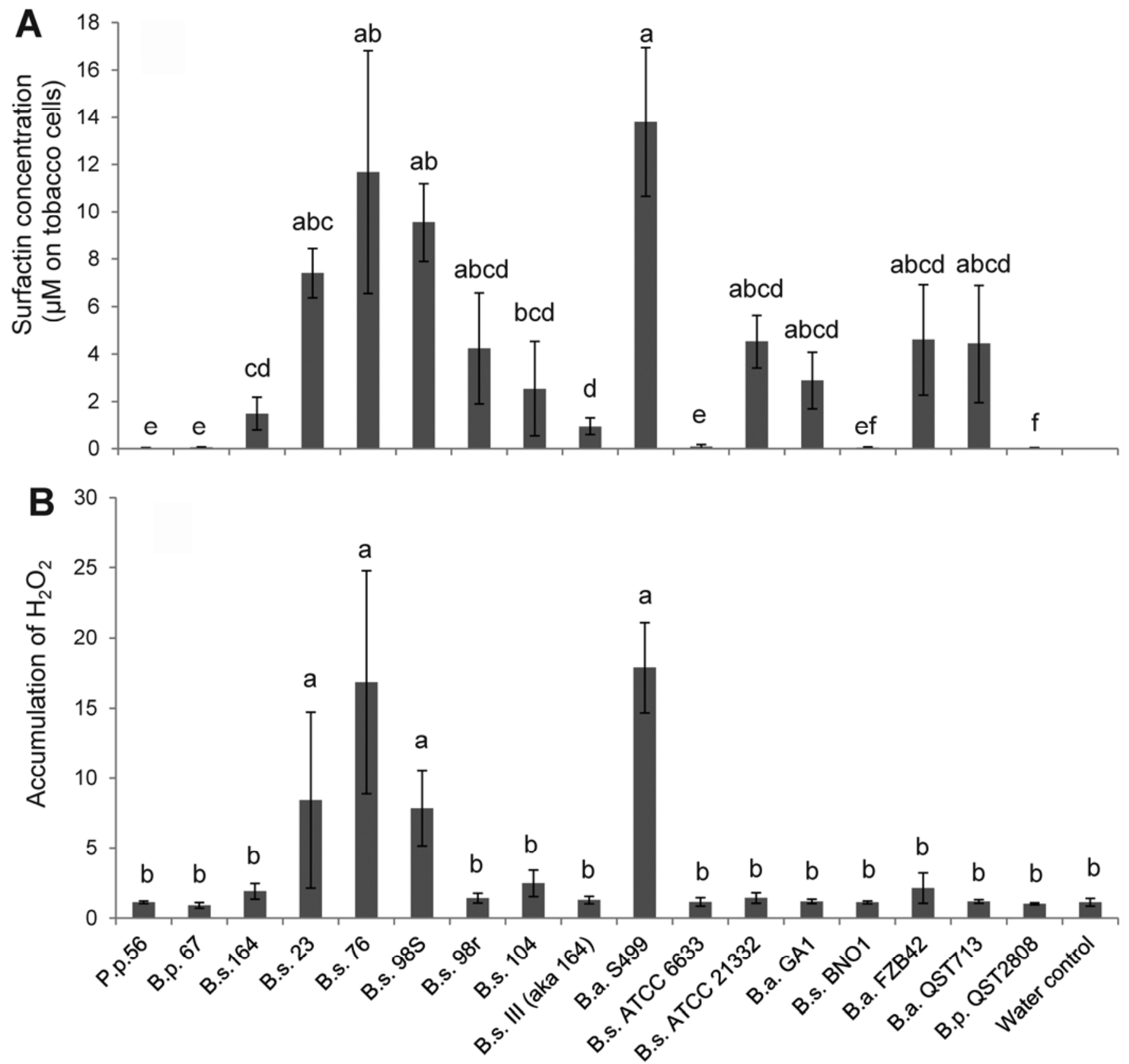

Fig. 2. Relationship between surfactin content and early event triggering for Bacillus supernatants. A, Surfactin concentrations added to tobacco cells when applying supernatants of the studied Bacillus strains. Bacteria were cultivated as biofilms in optimized medium in 96-well plates. Equal volumes of the various supernatants were tested on cultured tobacco cells. Means and standard deviations were calculated from the results of three independent cultures. B, Quantification of the oxidative burst (accumulation of $\mathrm{H}_{2} \mathrm{O}_{2}$ in the medium by the tobacco cells) caused by each Bacillus supernatant. The production of $\mathrm{H}_{2} \mathrm{O}_{2}$ was monitored by chemiluminescence from the ferricyanide-catalyzed oxidation of luminol. Means and standard deviations were obtained from three repeats of the oxidative burst experiment. In both panels, statistical analysis conducted on the three repeats showed aggregation of means in several siginificantly different groups represented by different letters on the mean bars. P.p. = Paenibacillus polymyxa, B.p. = B. pumilus, B.s. $=$ B. subtilus, and B.a. $=$ B. amyloliquefaciens. 
(leaves were detached to achieve more reproducible infection rates in our conditions, as discussed below), with a spore suspension of Botrytis cinerea. Disease reduction was rated 3 days postinfection, according to the percentage of spreading lesions that grew out of inoculation zones in treated plants compared with controls. Statistical analysis of disease reduction data (Fig. 4) showed that supernatant samples prepared from cultures of the strongest surfactin producer (S499) significantly triggered the most efficient protection of tobacco plants, with an average reduction of disease incidence of $41 \%$. By contrast, medium producers FZB42 and QST713 only triggered a weak protection not statitically different from the nonproducer strains. Meanwhile, 98S displayed an intermediate disease reduction between S499 and medium producers (Fig. 4). On the other hand, statistical analysis of disease incidence data showed that only S499 and 98S treatments trigger a significant protection compared with the water control. A correlation could be plotted between the LP concentration of the supernatant samples and the triggered protection on leaves $\left(\mathrm{R}^{2}=0.952\right)$ (Supplementary Fig. 2). These data showed that a dose-response relationship also occured between surfactin concentration and protection of tobacco against Botrytis cinerea.

\section{ISR triggered in tomato plants by living cells.}

We next wanted to test the disease control potential of living cells from the six strains against the same pathogen but using tomato as host plant. Solanum lycopersicum was chosen in order to extend our observations to another species of the Solanaceae and, secondly, to allow further study of the defense mechanisms possibly related to ISR (discussed below). In these assays, bacterial cells were inoculated in the peat substrate and disease severity caused by Botrytis cinerea was rated on the fourth leaves 5 weeks after bacterization and 3 days after infection.
Statistical analysis on Botrytis infection incidence indicated that all surfactin-producing strains significantly protected the plants from disease, while nonproducers were completely unefficient. Also, disease reduction data presented in Figure 5A show that both strong (S499 and 98S) and medium (QST713 and FZB42) producers were capable of inducing ISR to a significantly higher level than nonproducers (reduction in occurrence of spreading lesions as shown in Figure 5B), but no statistically significant difference was observed between strong and medium producers of surfactin. However, considering average values for disease reduction (Fig. 5A), S499 and 98S were more efficient at triggering ISR $(34 \% \pm 5 \%$ and $31 \% \pm$ $7 \%$ disease reduction) than QST713 and FZB42 $(22 \% \pm 3 \%$ and $26 \% \pm 3 \%$ ). However, the variability inherent to these ISR assays did not allow us to distinguish a statistically significant difference between the two groups. Differences in ISR potential between intermediate and very efficient surfactin producers are more contrasted by considering the percentages of strongly, moderately, and slightly diseased plants in each treatment. Globally, plants treated with intermediate producers such as QST713 were more often strongly diseased and less frequently lightly diseased as compared with plants treated with strong producers like B. amyloliquefaciens S499 (Fig. 5C) (detailed data for the three other strains were not included in the figure for purposes of clarity but are presented in Supplementary Figure 3). Again, treatment with $P$. polymyxa 56 (and B. subtilis BNO1) provided results similar to control plants.

Protection levels reached by S499 (34\% $\pm 5 \%)$ in this experiment are quite similar to those observed after treatment of tomato plants with $10 \mu \mathrm{M}$ purified surfactin $(32 \% \pm 13 \%$, mean value calculated also from three independent ISR assays using each 10 plants per treatment and performed under hydroponic conditions).

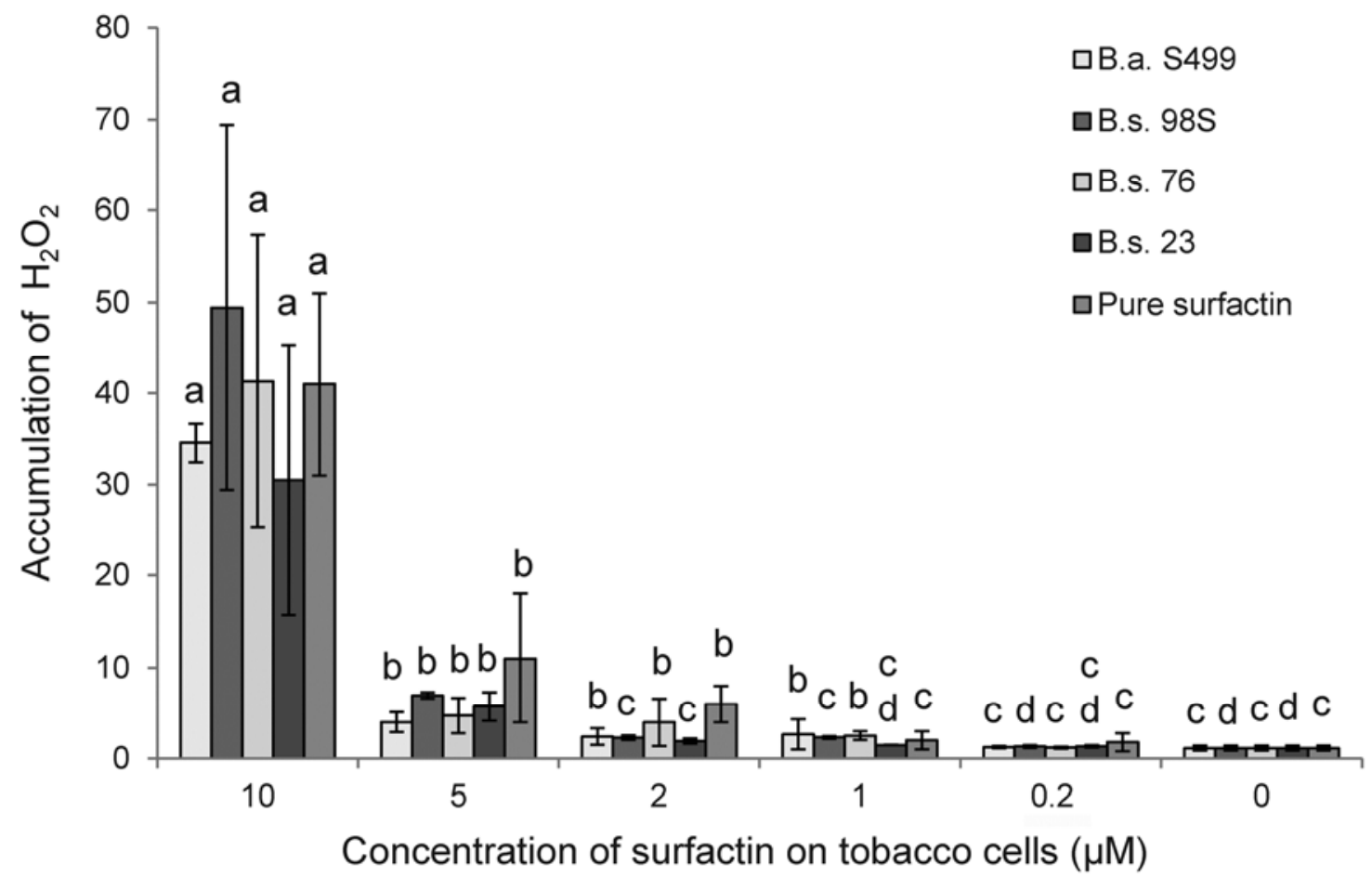

Fig. 3. Early event-triggering potential of serial dilutions of active Bacillus supernatants. Measurement of the oxidative burst response of tobacco cells (accumulation of $\mathrm{H}_{2} \mathrm{O}_{2}$ in the medium) triggered by diluted supernatants of the four active Bacillus strains and several dilutions of pure surfactin. The production of $\mathrm{H}_{2} \mathrm{O}_{2}$ was monitored by chemiluminescence from the ferricyanide-catalyzed oxidation of luminol. Means and standard deviations were calculated from the results of three independent oxydative burst experiments. Statistical analysis on the three repeats, conducted between several surfactin concentrations for the same strain, showed aggregation of means in several significantly different groups represented by different letters on the mean bars. B.s. $=$ B. subtilus and B.a. $=$ B. amyloliquefaciens. 


\section{Root colonization and surfactin production in recomposed exudates.}

We next wanted to establish whether this differential ability of the strains to trigger ISR may be due to differences in their ability to colonize the tomato rhizosphere or in their potential to produce elicitors in planta or both. However, an accurate determination of populations established on roots in these ISR assays was not possible due to the lack of suitable screening markers for most of these natural isolates. Alternatively, we used a gnotobiotic system in petri plates filled with nutrient agar on which bacterized tomato plantlets were grown without contamination by auxiliary microflora. Microscope visualization and plate counting of biofilm-related populations formed by the various isolates after 14 days of incubation indicated that all strains efficiently colonized plant roots to a relatively similar level except for BNO1, which displayed a significantly lower growth level (Fig. 6).

In addition, the studied strains were tested for their ability to use a medium simulating tomato root exudates for the production of surfactin. This experiment was based on the fact that the composition in organic substrates of exudates is very specific and the nutritional status is a key factor clearly impacting antibiotic production by root-colonizing bacteria, as we have previously shown for Bacillus LP production (Nihorimbere et al. 2009, 2012). In order to get closer to this natural nutritional context, bacteria were cultivated in a medium (referred as recomposed exudates [RE]) containing, as sole carbon sources, the sugars, organic acids, and amino acids typically found in tomato root exudates, as determined by Kamilova and collaborators (2006). As shown in Table 1, this RE medium supported growth of the six isolates to a similar level (analysis of variance [ANOVA], $\alpha=0.05$ ), which is in agreement with the similar colonization trends mentioned above. As revealed by LC-MS analysis of supernatants collected from these RE cultures, surfactin secretion was also efficient, with strains S499 and 98S producing the highest amounts of this LP, and no trace of the LP was observed in extracts from $P$. polymyxa 56 or $B$. subtilis BNO1. In this experiment, FZB42 produced a very low amount of surfactin, while QST713 displayed an intermediate production level (Table 1). This means that surfactin productivity per cell unit could be enhanced in the first two isolates in accordance with their higher efficiency to trigger systemic protection.

\section{Priming of the oxylipin pathway in resistant plants.}

Many works have reported the involvement of one or both the phenylpropanoid or oxylipin pathways as defense mechanisms stimulated in the host plant during PGPR-triggered ISR (Choudhary 2011; De Meyer and Hofte 1997; Mariutto et al. 2011; Ongena et al. 2004; Vanitha and Umesha 2011). Therefore, we wanted to evaluate the possible induction of both pathways in leaves of plants treated with $B$. amyloliquefaciens strains S499 and QST713 and B. subtilis BNO1 as representa-

Table 1. Bacterial population and surfactin concentration in the culture broth of the six selected Bacillus strains upon culture in recomposed exudates medium ${ }^{\mathrm{x}}$

\begin{tabular}{lcc}
\hline Strains & Population $^{\mathbf{y}}$ & Production $^{\mathbf{z}}$ \\
\hline Bacillus amyloliquefaciens S499 & $5.4 \pm 2.4 \mathrm{a}$ & $149 \pm 22 \mathrm{a}$ \\
B. subtilis 98S & $3.8 \pm 0.5 \mathrm{a}$ & $145 \pm 67 \mathrm{a}$ \\
B. amyloliquefaciens FZB42 & $5.6 \pm 3.0 \mathrm{a}$ & $18 \pm 2 \mathrm{~b}$ \\
B. amyloliquefaciens QST713 & $3.9 \pm 0.8 \mathrm{a}$ & $82 \pm 10 \mathrm{ab}$ \\
Paenibacillus polymyxa 56 & $1.3 \pm 0.4 \mathrm{a}$ & $0 \pm 0 \mathrm{~b}$ \\
B. subtilis BNO1 & $1.5 \pm 0.7 \mathrm{a}$ & $0 \pm 0 \mathrm{~b}$ \\
\hline
\end{tabular}

${ }^{\mathrm{x}}$ Means and standard deviations were calculated from two independent cultures. Statistical analysis on the two repeats showed aggregation of means in several significantly different groups represented by different letters

${ }^{\mathrm{y}}$ Bacterial population $\left(10^{8} \mathrm{CFU} / \mathrm{ml}\right)$.

${ }^{\mathrm{z}}$ Surfactin production $(\mu \mathrm{g} / \mathrm{ml})$.

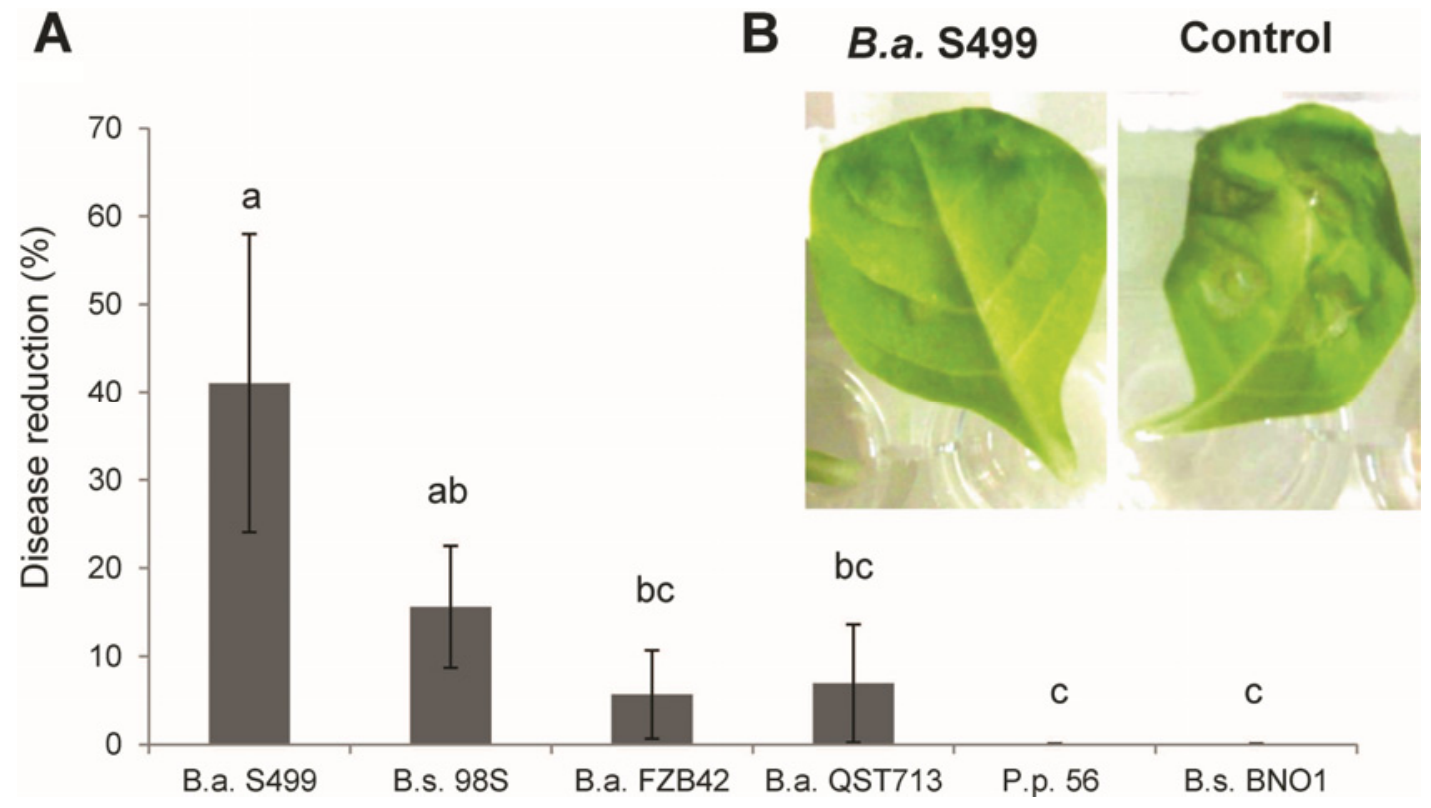

Fig. 4. A, Differential protection of tobacco leaves by six Bacillus supernatants against Botrytis cinerea infection. Plants were treated at the root level with extracts of biofilm cultures (supernatants depleted of sugars by C18 fractioning). After incubation, leaves were detached and infected with the pathogen. Disease reduction is calculated compared with water-treated control plants. Protection percentages were calculated by the formula $(\%)=100(1-x / y)$, in which $x$ and $y$ represent the total number of infected lesions on the leaves of treated and untreated plants, respectively. Each trial included five plants per treatement. Two leaves were inoculated for each of these plantlets (sixth and seventh leaf). The experiment was conducted twice. As data for the five plants per treatement were pooled in each expeirment, means and standard deviations were calculated on four data points each (two types of leaves and two independent experiments). Statistical analysis on the four repeats showed aggregation of means in several significantly different groups represented by different letters on the mean bars. B, Illustration of the symptoms caused by Botrytis cinerea on water control and Bacillus amyloliquefaciens S499 supernatant-treated tobacco plants. B.s. $=$ B. subtilus and B.a. $=$ B. amyloliquefaciens. 
tives of the three groups displaying differential ISR activities. However, no clear difference in the activity of phenylalanine ammonia lyase (PAL, the entry enzyme of the phenylpropanoid pathway) could be observed between control and Bacillustreated plants, whatever the isolate tested and the timing prior or post pathogen challenge (data not shown). By contrast, the activity of the lipoxygenase (LOX) enzyme (the entry enzyme of the oxylipin route) was significantly induced in B. amyloliquefaciens S499-colonized plants 2 days after pathogen challenge but not before infection (Fig. 7A). The level of LOX activation correlated well with the level of ISR response, since a slight but not significant increase in activity was observed in leaves of plants treated with the weaker resistance-inducer $B$. amyloliquefaciens QST713, and no significant modification of LOX activity compared with control was observed for $B$. subtilis BNO1 (Fig. 7A). Moreover, enhanced LOX activity in S499-treated plants correlated time-wise with a significant accumulation of transcripts of genes corresponding to the two isoforms, TomLOXD and TomLOXF (Fig. 7B), that are associated with PGPR-induced ISR (Mariutto et al. 2011). Interest-
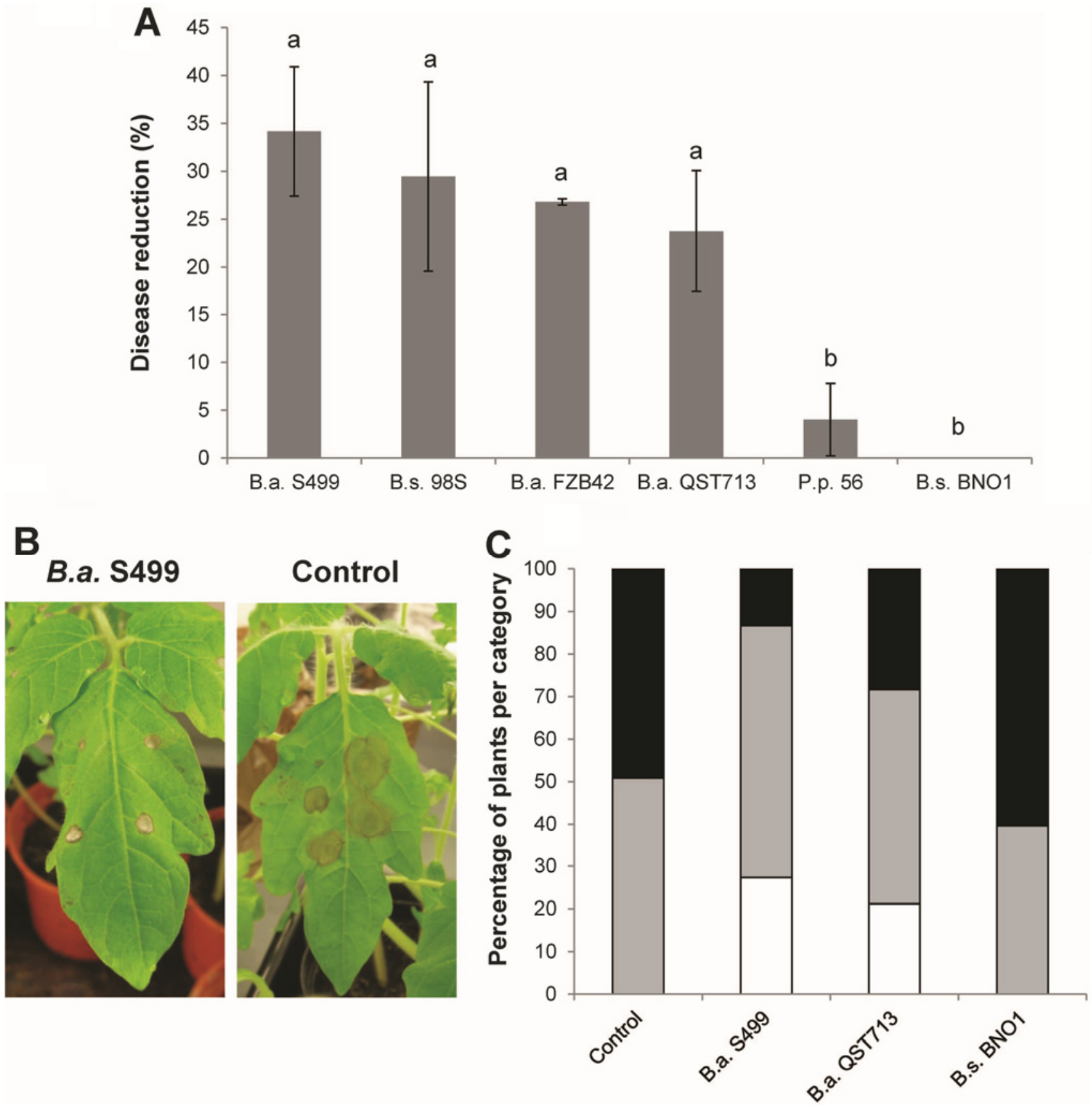

Fig. 5. Differences in triggered protection in tomato plants for six Bacillus strains against Botrytis cinerea infection. A, Disease reduction on tomato leaves inoculated with Botrytis cinerea after root inoculation with live cells of the six selected Bacillus strains compared with uninoculated control plants. Protection percentages were calculated by the formula $(\%)=100(1-x / y)$, in which $x$ and $y$ represent the total number of infected lesions on the leaves of treated and untreated plants, respectively. Means and standard deviations were calculated on the basis of three independent experiments, each containing seven plants per treatment. Statistical analysis on the three repeats showed aggregation of means in several significantly different groups represented by different letters on the mean bars. B, Reduction in occurrence of typical spreading lesions as compared between diseased control plants and plants inoculated with S499 before infection. C, For three selected Bacillus strains, percentage of plants in the experiment described in A presenting 0 to 3 lesions (low disease severity, white bars), 4 to 6 lesions (intermediate disease severity, gray bars), or 7 to 10 lesions (high disease severity, black bars). Presented data are means of three independent experiments. B.a. = B. amyloliquefaciens, B.s. = B. subtilus, and P.p. = Paenibacillus polymyxa. 
ingly, the enhanced LOX expressions resulted in a significant accumulation of their products, 13-hydroperoxy-octadecadienoic (13-HPOD) and 13-hydroperoxy-octadecatrienoic (13HPOT) acids, 2 days after infection (Fig. 7C). In a way very similar to S499, root treatment with pure surfactin primed the plant to react more promptly to Botrytis cinerea attack on leaves. Elicitation with surfactin actually resulted in a transient but significant increase in LOX enzyme activity in infected leaves two days after pathogen challenge (Fig. 7A and B). Also, the same hydroperoxide products as in S499 treated plants significantly accumulated in surfactin-elicited tomatoes upon Botrytis cinerea infection (Fig. 7C). Again such stimulation was transient, since those differences were no longer observed at 4 days postinfection (data not shown).

\section{DISCUSSION}

Surfactin biosynthesis is widespread among plant-associated Bacillus isolates. This is not surprising, considering the various benefits it provides for the ecological fitness of the producing bacterium. Indeed, efficient root colonization partly relies on the potential of bacterial cells to move on the root surface to reach new microniches with greater amounts of nutrients and on the ability to evolve on roots as biofilm-related structures (Bais et al. 2004; Ramey et al. 2004). As a matter of fact, Bacillus swarming (one of the two types of motility) on solid surfaces has been clearly linked to the secretion of surfactin acting as wetting agent (Hamze et al. 2009; Kinsinger et al. 2003; Raaijmakers et al. 2010). It is also obvious that surfactin

A
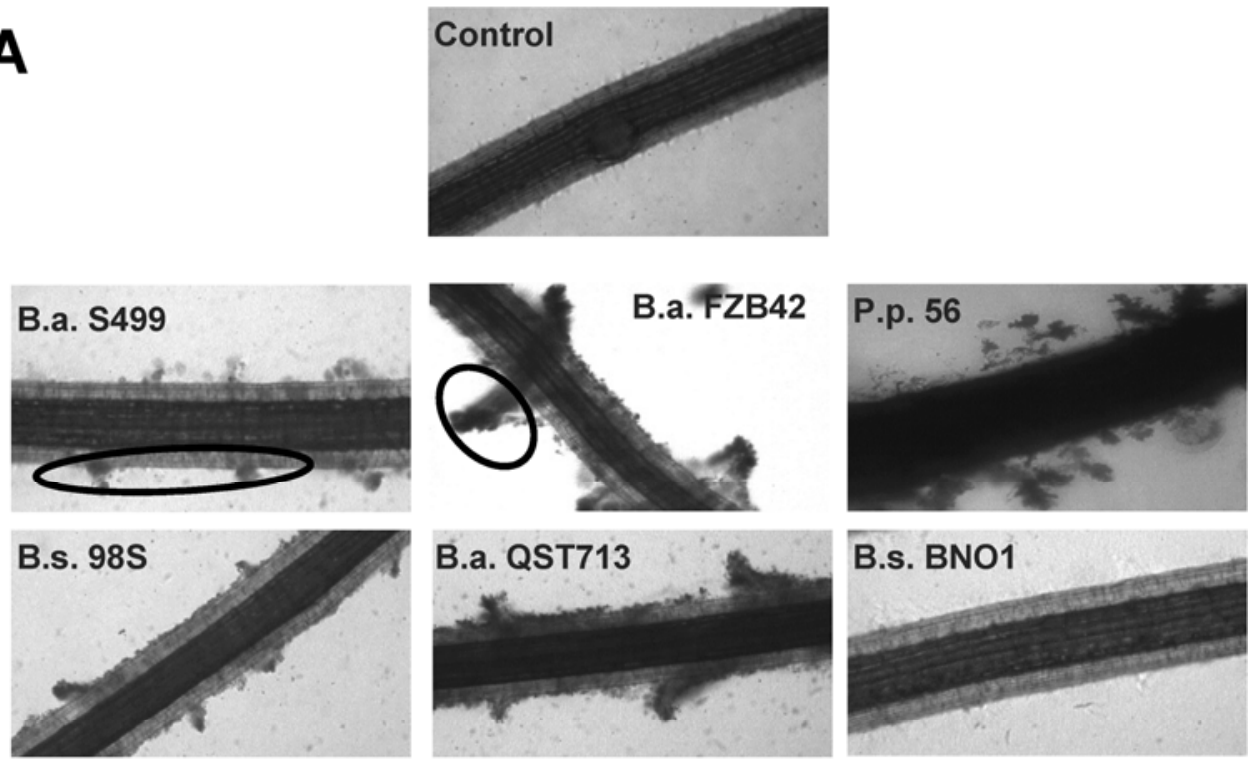

B

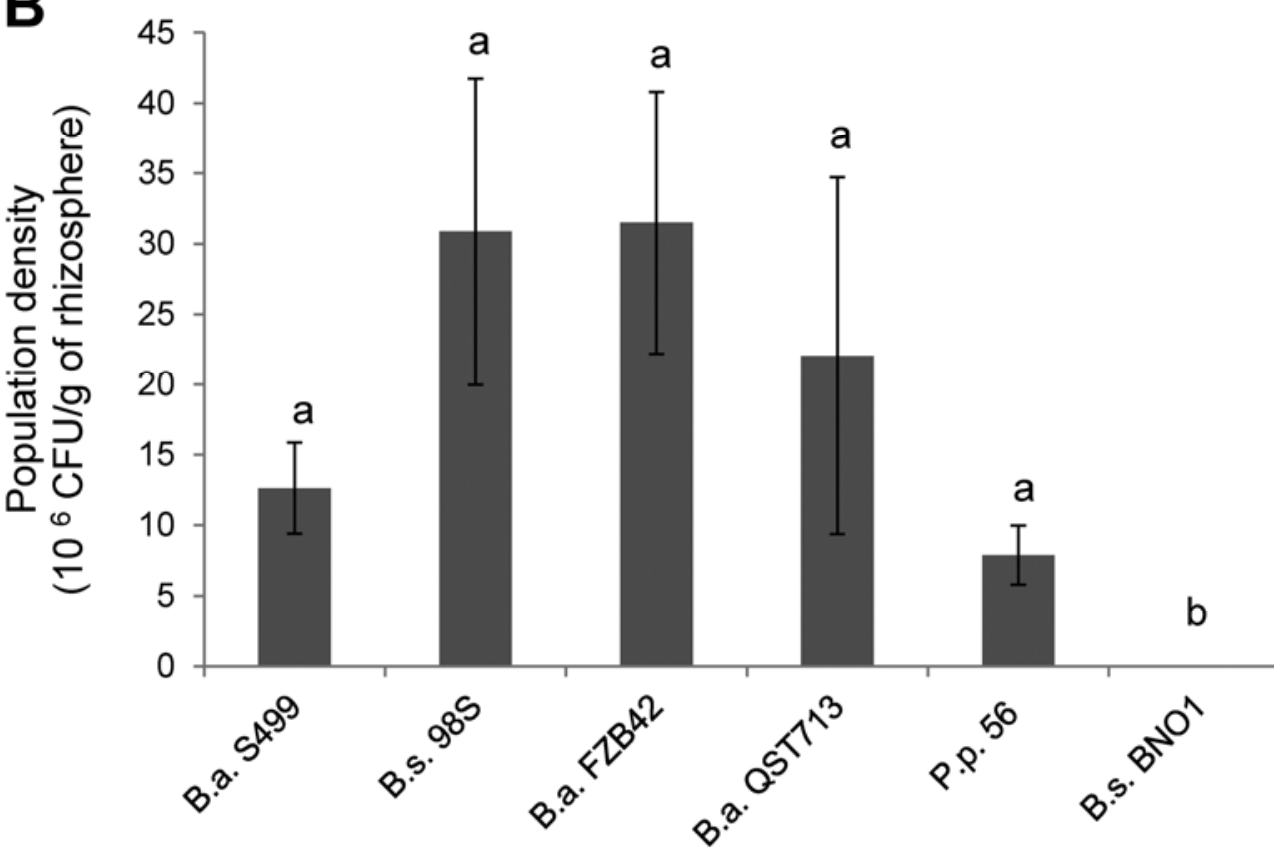

Fig. 6. A, Comparison of biofilm formation on tomato roots by six Bacillus strains. Illustration of the observed biofilm (circled in black) for the six selected Bacillus strains 2 weeks after inoculation on tomato plantlets grown in vitro on Hoagland agar. Pictures were taken using a light microscope equipped with a $10 \times$ objective. Presented photographs are representative of observations conducted on three plantlets per treatment. B, Colonization levels of the studied strains on the in vitro plantlets. Presented data are means and standard deviations calculated from plate counts on three plantlets (one plate count per plantlet). Statistical analysis on the three repeats showed aggregation of means in several significantly different groups represented by different letters on the mean bars. B.a. = B. amyloliquefaciens, P.p. = Paenibacillus polymyxa, and B.s. = B. subtilus. 
positively influences biofilm formation by Bacillus spp. (Hofemeister et al. 2004; López and Kolter 2010). The LP likely plays a signaling role, driving cell subpopulations to produce extracellular matrix (López et al. 2009).

In addition, a pivotal role of this compound in plant-Bacillus interactions is further illustrated by its host immunization activity resulting in enhanced resistance towards phytopathogens. Involvement of surfactin as ISR elicitor has been demonstrated in bean and tomato (Ongena et al. 2005a and b, 2007) but also in Arabidopsis thaliana (M. Ongena, unpublished data) and melon plants (García-Gutiérrez et al. 2012). It thus appears that this molecule is active in triggering ISR in a broad range of host plants. Such a low specificity may be explained by the fact that the perception of surfactin by plant cells may rely on an uncommon mechanism based on interaction with the lipid bilayer fraction of plasma membrane rather than via recognition by some proteic receptor, as established for other elicitors (Henry et al. 2011).

Some bacterial species belonging to the Pseudomonas and Bacillus genera are well-known for their ability to trigger ISR, but most studies reported up to this time have focused on the determination of the active compound produced by one specific strain under particular conditions. In line with this, a key role of surfactin for the plant-immunizing potential of the producing

A
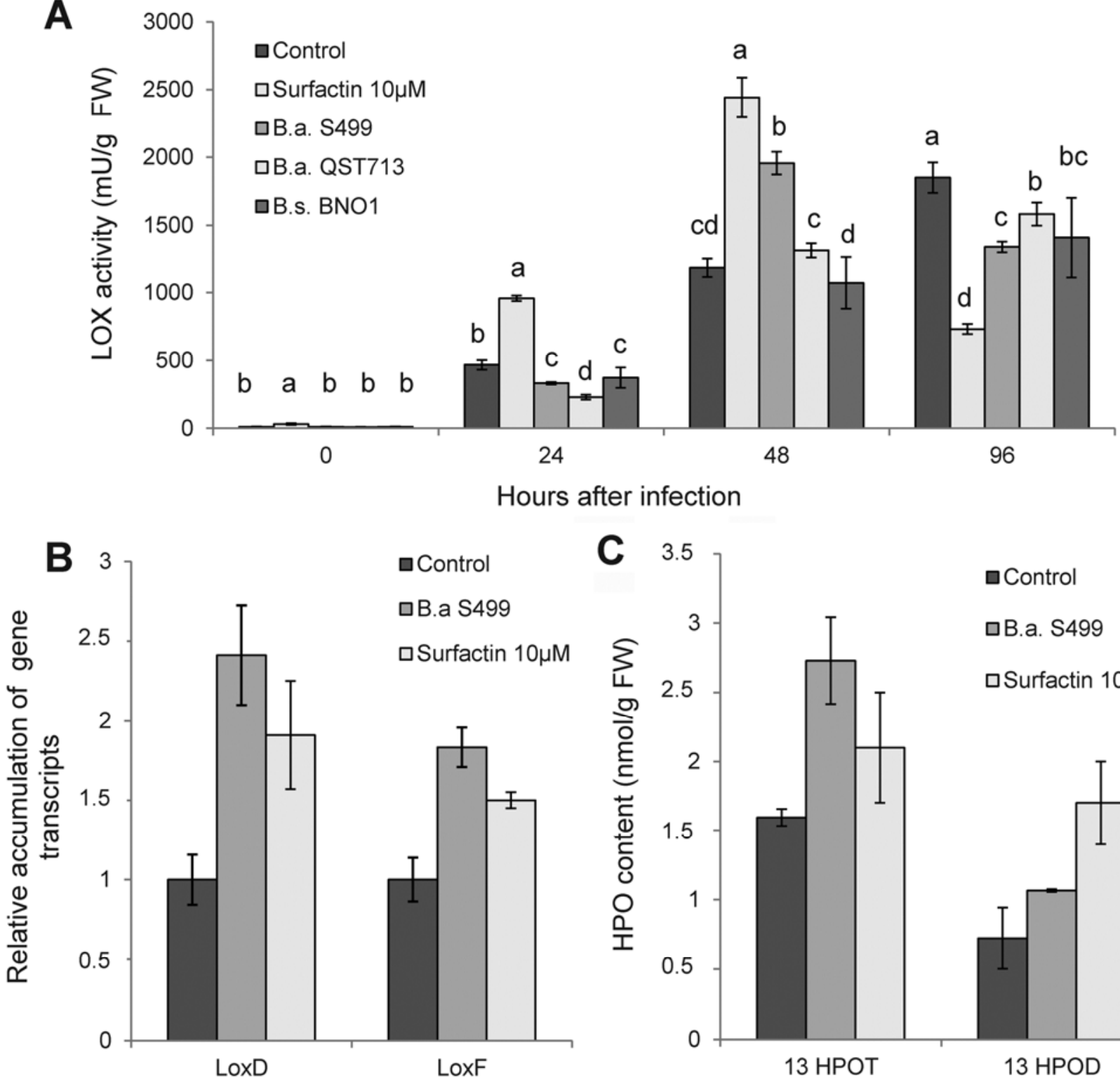

Fig. 7. Stimulation of lipoxygenase (LOX) pathway in leaves of tomato plants inoculated with strong, medium, and nonproducer strains, Bacillus amyloliquefaciens (B.a.) S499, B. amyloliquefaciens QST713, and B. subtilis (B.s.) BNO1 respectively. A, Time course evolution of LOX activity in plants bacterized with B. amyloliquefaciens S499, B. amyloliquefaciens QST713, and B. subtilis BNO1. Samples were collected before infection by Botrytis cinerea and 1,2, and 4 days thereafter. Data are means and standard deviations calculated from three measurements on two independently prepared extracts. In each experiment, statistical analysis on the six repeats (six samples per treatment) showed aggregation of means in several significantly different groups represented by different letters on the mean bars. Statistical comparaison was conducted between treatements for a same sampling time. B, Relative expression of TomLoxD and TomLoxF and $\mathbf{C}$, fatty acid hydroperoxide accumulation in B. amyloliquefaciens S499 as compared with control and surfactintreated plants 2 days after pathogen inoculation were analyzed by semiquantitative reverse transcription-polymerase chain reaction and ultrahigh pressure liquid chromatography-diode array detector, respectively. Data are means and standard deviations calculated from three measurements on two independently prepared extracts. In each experiment, the different treatments (six data points per treatment) were compared by Student's $t$-test $(\alpha=0.05)$. The three panels of the figure show data from a representative experiment that was repeated on two independent biological replicates. HPOD and HPOT, hydroperoxy-octadecadienoic and hydroperoxy-octadecatrienoic acids, respectively. 
bacterium has been mainly evidenced in the case of strain S499 (Jourdan et al. 2009). Surprisingly, no study has yet been done to generalize these observations to other strains of the same or closely related species. Results from the work described here strongly suggest that such a key role of the LP for ISR triggering can be extended to other Bacillus isolates. To the best of our knowledge, this is the first comparative study demonstrating the importance of a single compound for plant immunization by members of the B. subtilis/amyloliquefaciens group. We used various approaches to come to this conclusion.

First, both early defense-inducing and ISR-triggering activities of the strain-specific extracts correlate very well with their surfactin content. Moreover, the amplitude of the plant response observed following treatment with active supernatant extracts is very similar to the one induced by pure surfactin at the same concentration. It is reported for oxidative burst stimulation in cultured cells (Fig. 3), but it also applies to ISR in tobacco plants, since comparable levels of ISR induced by S499 and 98S extracts (approximately 25 to $30 \%$ disease reduction [Fig. 4]) were previously observed by treating plants with $10 \mu \mathrm{M}$ purified surfactin (Henry et al. 2011).

Second, assays performed on tomato plants treated with living cells also show that disease protection correlates with the potential of the strains to produce this LP not only in optimized medium but also when submitted to a nutritional status mimicking the one imposed in the rhizosphere by exudation of plant roots (Table 1). The lower efficacy of strains FZB42 and QST713 to stimulate ISR in tomato as compared with $\mathrm{S} 499$ or $98 \mathrm{~S}$ is probably not due to reduced rhizosphere fitness, since they form similar consistent biofilms on plantlets (Fig. 6). Interestingly, disease reduction of approximately $30 \%$ provided by the most efficient isolates S499 and 98S is very similar to the protection level observed after treatment with $10 \mu \mathrm{M}$ purified surfactin in hydroponic conditions. Moreover, we have recently demonstrated that the LP signature of S499 is substantially modulated upon living roots compared with laboratory conditions in favor of surfactin. Indeed, much greater proportions of this LP than fengycins and iturins were found in the tomato rhizosphere (Nihorimbere et al. 2012). Such efficient surfactin production in planta is thus in support of the high systemic resistance-triggering potential of S499. Surfactin secretion by root colonizing cells has also been reported for strains QST713 and FZB42 (Fan et al. 2011; Kinsella et al. 2009). However, compared with S499, these two strains are less prone to produce surfactin in the presence of carbon sources typically found in tomato exudates and, probably, also less efficient at secreting this LP in planta. As the eliciting activity of the molecule is dose-dependent, it may explain why ISR activity of those strains on tomato is weaker (but still significant) than for S499.

Third, in support to the macroscopically observed ISR phenotype, we have also quantified some markers of this phenomenon in order to associate disease reduction with specific molecular events involved in the defense response of the host induced by the various strains. The activity of the PAL enzyme was not systemically stimulated in leaves upon root treatment with the tested Bacilli strains. It would, therefore, be unlikely that the observed resistance was associated with an increase in lignification or accumulation of antifungal phenylpropanoids (Fraser and Chapple 2011). By contrast, our results illustrate a global stimulation of the LOX-initiated oxylipin pathway, which converts unsaturated fatty acids into highly reactive hydroperoxides that can be further transformed by other enzymes into different defense metabolites (Shah 2005). Both LOX gene transcription and enzyme activity were induced by strain S499. This resulted in accumulation of their products 13-HPOD and 13-HPOT acids retaining antifungal activity (Mariutto et al. 2011; Prost et al. 2005). This phenomenon was stimulated be- tween 24 and $48 \mathrm{~h}$ after pathogen infection and is, thus, timely activated to counteract disease development. Indeed, even if there are no clearly visible symptoms at that time, a fast defensive response has to be mounted upon first attempts of Botrytis cinerea penetration, which occur $24 \mathrm{~h}$ after infection under our experimental conditions (Mariutto et al. 2011; Ongena et al. 2007). The observed trends in LOX activity are, thus, in agreement with the disease reduction potential of strain S499. A very similar stimulation of the oxilipin pathway was observed upon treatment with pure surfactin (Fig. 7), again indicating that the global activity of S499 is mimicked by applying the LP alone. This provides additional evidence at the molecular level for its crucial role in ISR. No LOX stimulation was noted upon treatment with the less-active strains, but a certain level of disease resistance was provided by treating tomato plants with QST713 and FZB42, suggesting that other pathways than LOX and PAL can be activated to counteract Botrytis cinerea infection. Considered globally, our data illustrate that a certain threshold in surfactin concentration in the rhizosphere is necessary to trigger ISR in tomato and that it also correlates with the stimulation of defense pathways in that host.

Compared with S499, extracts prepared from FZB42 and QST713 cultures with high concentrations of iturins (or their bacillomycin-type variants) and fengycins but lower contents in surfactin, were less active on both tobacco cultured cells and plantlets. Also, extracts from $98 \mathrm{~S}$ with similar surfactin but higher iturin and fengycin content had similar effects on plantlets and cells as S499. In agreement with previous data (Henry et al. 2011; Jourdan et al. 2009), it shows that the two other main LP families are very poorly or not active as elicitors of early defense response and systemic protection in that plant. No iturin, fengycin, or surfactin were detected in the inactive supernatant of $P$. polymyxa 56, but this strain does efficiently secrete fusaricidins and their structurally-related LI-F variants as LP products with strong antifungal activity (Debois et al. 2013). However, it appears from our data that these molecules do not retain ISR-triggering potential in the plants tested. It also applies for any other soluble compound with reduced hydrophobicity that could be secreted by all the Bacillus isolates tested, such as aminobenzoic acid recently identified as a potential ISR elicitor (Yang et al. 2011).

In ISR assays involving living cells, plant resistance could also be due to the emission of butanediol and acetoin volatiles (Ryu et al. 2004). Gas chromatographic-MS analyses revealed that all the tested strains except BNO1 are able to produce these volatiles to a similar extent upon growth on rich medium, using the methodology described by Ryu and collaborators (2004) (Supplementary Fig. 4). However, upon growth of strains on RE medium, volatile emission was markedly reduced and trace amounts of butanediol and acetoin could only be detected in the gas phase of S499 and FZB42 cultures but not for 98S and QST713 (data not shown). This suggests that tomato exudates are not conducive for an efficient release of those volatiles. So, globally, even if the involvement of volatile compounds cannot be completely ruled out, ISR potential of the strains tested here does not seem to correlate with some naturally higher productivity of acetoin and 2,3-butanediol in vitro.

In summary, the comparative approach used in this work strongly suggests that the key role played by the surfactin LP in plant defense elicitation not only applies to one particular strain (S499) but, also, to other isolates belonging to the B. subtilis/ amyloliquefaciens complex. Screening for isolates with huge potential for ISR stimulation is interesting for the development of new PGPR-based biopesticides, given the importance of this plant immunization process in the global biocontrol activity provided by those beneficial microbes. As the ISR potential of Bacillus strains is tightly related to their capacity to efficiently 
produce surfactin, a first necessary step is to look for the presence of $s r f$ genes coding for the nonribosomal peptide synthase biosynthesis machinery. This approach could be combined with polymerase chain reaction (PCR) screening for other important biocontrol marker genes as reported by Joshi and collaborators (2006). Consistent expression of this genetic potential must be, of course, counterchecked by HPLC-electrospray ionization-MS analyses of LP in supernatant extracts after growth under optimized conditions for production. One step further in the screening strategy, assays for stimulation of early defense events in cultured cells may be used to evaluate the eliciting activity of the bacterial extracts. Indeed, our data clearly suggest a positive correlation between the potential to stimulate ROS production in cultivated cells and disease protection in whole plants, even if not of the same species (tomato and tobacco) but of the same taxonomical family (Solanaceae). However, this is not sufficient, and the ecological fitness of the producing isolates has also to be considered. Cells should efficiently colonize and adequately use root exudates for efficient production of the LP in order to reach a certain threshold amount in the rhizosphere. Our results strongly suggest that this rhizosphere fitness may vary from one strain to another, and many further efforts must be made to provide insights into the physiological regulatory processes that could explain such differences.

\section{MATERIALS AND METHODS}

\section{Bacterial strains.}

Bacillus sp. strains S499 (Ongena et al. 2005a and b) and GA1 (Arguelles-Arias et al. 2009) have been previously described and strains FZB42 and QST713/QST2808 were provided, respectively, by $\mathrm{R}$. Borriss of Humboldt University, Berlin, and by J. Margolis of the Agraquest society (Davis, CA, U.S.A.). The BNO1 and American Type Culture Collection strains 6633 and 21332 were obtained from the laboratory collection. Bacillus sp. strains 98S, 23, 67, 164, 98r, 104, III, and $P$. polymyxa 56 were provided by B. McSpadden Gardener from Ohio State University (Columbus, OH, U.S.A.).

\section{Agitated cultures.}

Bacteria were streaked on Luria medium (per liter: peptone, $8 \mathrm{~g}$; yeast extract, $4 \mathrm{~g}$; NaCl, $4 \mathrm{~g}$; glucose, $0.8 \mathrm{~g}$; agar, $12.5 \mathrm{~g}$ ) and were incubated overnight at $30^{\circ} \mathrm{C}$. These colonies were used to inoculate Erlenmeyer flasks $(250 \mathrm{ml})$ containing $50 \mathrm{ml}$ of a medium optimized for LP production, Opt medium (Jacques et al. 1999). These flasks were shaken during 3 days at $30^{\circ} \mathrm{C}$.

\section{Biofilm cultures.}

Static cultures were conducted in Sterilin 96-well plates (conical sterile non-cell culture treated plates; Thermo Fisher Scientific Inc., Waltham, MA, U.S.A.). Each well contained $150 \mu \mathrm{l}$ of Opt medium (Jacques et al. 1999). For inoculum preparation, strains were streaked on Luria medium and were incubated overnight at $30^{\circ} \mathrm{C}$. These colonies were used to inoculate agitated overnight precultures, which were conducted in $\mathrm{Opt}$ medium at $30^{\circ} \mathrm{C}$. These precultures were stopped when their optical density at $600 \mathrm{~nm}\left(\mathrm{OD}_{600 \mathrm{~nm}}\right)$ was between 0.5 and 1 . The obtained active bacterial populations were centrifuged and were resuspended in saline solution ( $9 \mathrm{~g}$ of $\mathrm{NaCl}$ per liter) to an $\mathrm{OD}_{600 \mathrm{~nm}}$ of 0.1 . A volume of $5 \mu \mathrm{l}$ of this inoculum was applied to each well, and inoculated plates were incubated statically for $19 \mathrm{~h}$ at $30^{\circ} \mathrm{C}$.

\section{LC-MS quantification of LP.}

Samples were analyzed by reverse phase HPLC-MS (HPLC Waters Alliance 2695 diode array detector; Waters, Zellik, Bel- gium) coupled with a single quadrupole mass spectrometer (Waters SQD mass analyzer) on an X-terra MS (Waters) $150 \times$ $2.1 \mathrm{~mm}, 3.5 \mu \mathrm{m}$ column. We used a method based on acetonitrile gradients that allowed the simultaneous detection of all three LP families. Elution was started at $45 \%$ acetonitrile (flow rate of $0.65 \mathrm{ml} / \mathrm{min}$ ). After $10 \mathrm{~min}$, the percentage of acetonitrile was brought up to $95 \%$ and held for $9 \mathrm{~min}$. Then, the column was stabilized at an acetonitrile percentage of $45 \%$ for 5 min. Compounds were identified on the basis of their retention times compared with authentic standards and the masses detected in the SQD. Ionization and source conditions were set as follows: source temperature, $130^{\circ} \mathrm{C}$; desolvation temperature, $280^{\circ} \mathrm{C}$; nitrogen flow, 600 liters per hour]; cone voltage, $100 \mathrm{~V}$.

\section{Tobacco cells cultures.}

The suspended tobacco cells, Nicotiana tabacum BY-2, were cultured in $250 \mathrm{ml}$ flasks containing $50 \mathrm{ml}$ of plant cell medium (Jourdan et al. 2009). The flasks were incubated in the dark under agitation $(90 \mathrm{rpm})$ at $25^{\circ} \mathrm{C}$. The tobacco cells were subcultured every 7 days; $1.6 \mathrm{ml}$ of a mother culture were transferred to a flask containing fresh medium.

\section{Oxidative burst detection on tobacco cells.}

We quantified $\mathrm{H}_{2} \mathrm{O}_{2}$ production, in 5-day-old tobacco cell suspensions after exposition to elicitors, through a chemiluminescence assay. Cells were filtered, rinsed, and resuspended in HEPES medium to a cell density of 60 to $90 \mathrm{mg} / \mathrm{ml}$ (wet weight of the suspension recovered by filtration) (Jourdan et al. 2009) and were then incubated for $1 \mathrm{~h}$ to reduce stress.

First, the base level of $\mathrm{H}_{2} \mathrm{O}_{2}$ production of this specific plant cell population was measured. The assay was conducted according to Jourdan and colleagues (2009), except $50 \mu \mathrm{l}$ of cell suspension were used instead of $100 \mu \mathrm{l}$ and the luminescence signal was integrated, at one measurement per second, over the first $10 \mathrm{~s}$ after the beginning of the reaction. After taking this measurement, the elicitor or sample was added to the suspension, and $\mathrm{H}_{2} \mathrm{O}_{2}$ production was measured every 2 min, starting at the third minute after adding the elicitor. The accumulation of $\mathrm{H}_{2} \mathrm{O}_{2}$ caused by each sample was calculated as being the ratio of the highest observed concentration of hydrogen peroxide on the base level concentration $\left(\mathrm{H}_{2} \mathrm{O}_{2}\right.$ level before addition of the elicitor).

\section{Sample preparation for oxidative burst.}

In the comparative assay including 17 strains, crude supernatants were all diluted 6.67 times with distilled water before application to tobacco cells to bring them into an adequate concentration range ( 0 to $20 \mu \mathrm{M}$ of surfactin on the tobacco cells). For each strain, $75 \mu \mathrm{l}$ of this diluted supernatant were added to $500 \mu \mathrm{l}$ of tobacco cell suspension.

For the oxidative burst on diluted samples, supernatants or purified surfactin were mixed with distilled water to obtain the range of tested concentrations. For each dilution, $90 \mu \mathrm{l}$ were applied to $600 \mu \mathrm{l}$ of tobacco cells (same volume ratio as above).

For the tests on fractioned samples, supernatants were treated as follows. Each sample was loaded onto a reverse phase (C18) cartridge (Grace Maxi-CleanTM SPE 300 mg; Alltech Associates Inc., Lokeren, Belgium) that was then flushed with air (sample WATER 1), rinsed with water, and flushed again (sample WATER 2). The cartridge was then successively eluted with $20,40,60$, and $100 \%$ methanol in water and flushed with air between each solvent. The volumes of loaded sample and of each solvent were identical. Fractions were dried using a Speed-Vac apparatus and were resuspended in their original methanolic solvent, obtaining a concentration factor of 7.1. For each treatment, $14.50 \mu \mathrm{l}$ of this concentrated 
sample were applied on $400 \mu \mathrm{l}$ of tobacco-cell suspension, except for the concentrated $100 \%$ methanol fraction, for which $11.52 \mu \mathrm{l}$ were applied. Thus, the concentrations of metabolites applied on the tobacco cells were about four and five times lower than those found in the crude supernatant.

\section{Cultivation and preparation of Botrytis cinerea.}

The pathogen strain used in this work was Botrytis cinerea $\mathrm{R} 16$. This fungus was maintained by subculturing it every two weeks on potato dextrose agar medium. Fifteen-day-old cultures were scraped using salt peptone water (per liter: $\mathrm{NaCl}, 5 \mathrm{~g}$; peptone, $1 \mathrm{~g}$; Tween $80,2 \mathrm{ml}$ ) that was then filtered to eliminate mycelium debris. The obtained spore suspension was centrifuged and spores were resuspended in preserving liquid $(8.5 \%$ defatted milk and $10 \%$ glycerol in water). This new sample was stored at $-80^{\circ} \mathrm{C}$. When needed, this sterile suspension was thawed out in a refrigerator and was centrifuged. Spores were then washed with de-ionized water (to eliminate storage liquid) and resuspended in infection solution (described below).

\section{ISR on cut tobacco leaves.}

Bacterial supernatants were prepared by cultivating the strains under biofilm conditions for 3 days at $30^{\circ} \mathrm{C}$ in static flasks containing Opt medium (20 ml medium in a $100-\mathrm{ml}$ flask). Active cell populations used to inoculate these cultures were obtained by streaking strains on Luria medium and overnight incubation at $30^{\circ} \mathrm{C}$.

The biofilm cultures were centrifuged and processed to eliminate residual sugars. This step was necessary, as pure supernatants caused important contaminant growth around the tobacco roots. Sample clean-up was accomplished by following the same procedure as for the samples in the oxidative-burst assay except the only solvents used here were water and pure methanol. After this procedure, cleaned-up samples were concentrated using a Speed-Vac apparatus at $25^{\circ} \mathrm{C}$ and 30 megabars for $24 \mathrm{~h}$. The obtained centrifugation sediments were resuspended in methanol.

Tobacco plants were cultivated in rock wool in commercial hydroponic systems (Araponics SA, Liège, Belgium). Hoagland solution was used as a nutrient base (in milligrams per liter: $\mathrm{Ca}\left(\mathrm{NO}_{3}\right)_{2} \cdot 4 \mathrm{H}_{2} \mathrm{O}, 825 ; \mathrm{KNO}_{3}, 316 ; \mathrm{KH}_{2} \mathrm{PO}_{4}, 170 ; \mathrm{MgSO}_{4} \cdot 7 \mathrm{H}_{2} \mathrm{O}$, 513; $\mathrm{H}_{3} \mathrm{BO}_{3}, 1.40 ; \mathrm{MnCl}_{2} \cdot 4 \mathrm{H}_{2} \mathrm{O}, 0.90 ; \mathrm{ZnSO}_{4} \cdot 7 \mathrm{H}_{2} \mathrm{O}, 0.10$; $\mathrm{CuSO}_{4} \cdot 5 \mathrm{H}_{2} \mathrm{O}, 0.05 ; \mathrm{NaMoO}_{4} \cdot 2 \mathrm{H}_{2} \mathrm{O}, 0.02 ;$ EDTA.2Na, 5.20; $\left.\mathrm{FeSO}_{4} \cdot 7 \mathrm{H}_{2} \mathrm{O}, 3.90\right)$. Two seeds were sown per seed holder and double germinations were separated 2 weeks after seeding. In total, plants were incubated for 5 weeks at $30^{\circ} \mathrm{C}$, with a circadian cycle of $16 \mathrm{~h}$ of light and $8 \mathrm{~h}$ of darkness.

After this growth period, plants were transferred in 5-ml polystyrene tubes that had been darkened using aluminum foil and contained the treatments. These consisted of the cleanedup concentrated samples diluted up to their initial concentrations using Hoagland solution. The tubes containing the tobacco plants were placed in Araponics systems that contained some water to promote ambient humidity. This system was incubated for $24 \mathrm{~h}$ at $22^{\circ} \mathrm{C}$, under a circadian cycle comprising $10 \mathrm{~h}$ of light and with a humidity regulated to approximately $60 \%$. After this period, the sixth and seventh leaf of each plant were cut off and placed in 12-well plates, their petioles were immersed in 100 times diluted Hoagland solution. The plates were placed in small boxes containing tap water for humidity and were incubated at room temperature. After $24 \mathrm{~h}$, each leaf was infected with four drops of Botrytis cinerea suspension, prepared as described above, containing $5 \times 10^{5}$ spores per milliliter of tobacco-infection solution $(50 \mathrm{mM}$ glucose and $34 \mathrm{mM}$ $\mathrm{KH}_{2} \mathrm{PO}_{4}$ ). Infected leaves were incubated in the same system for 3 days. We used this detached-leaf system because it provided much more consistent infection rates (and, therefore,
ISR results) throughout independent assays than working with whole tobacco plants.

Lesions were scored as infected when the fungus had caused damage outside the initial inoculation spot. Protection percentages were calculated by the formula $(\%)=100(1-x / y)$, in which $x$ and $y$ represent the total number of infected lesions on the leaves of treated and untreated plants, respectively.

\section{ISR induction in tomato plants.}

Bacterial strains were streaked on solid Luria medium and were incubated overnight at $30^{\circ} \mathrm{C}$. These colonies were used to inoculate 100 - $\mathrm{ml}$ flasks containing $20 \mathrm{ml}$ of optimized medium, which were then agitated $(150 \mathrm{rpm})$ for $24 \mathrm{~h}$ at $30^{\circ} \mathrm{C}$. Next, $150 \mu \mathrm{l}$ of the obtained culture were spread out on solid Luria medium. These petri dishes were then incubated again overnight at $30^{\circ} \mathrm{C}$. From this point on, manipulations were conducted under clean but nonsterile conditions.

The obtained active bacterial populations were scraped off the plates using a sterile solution of $\mathrm{MgSO}_{4} \cdot 7 \mathrm{H}_{2} \mathrm{O}(10 \mathrm{mM})$. The optical density of the suspension was determined, and it was diluted using Hoagland solution to a cellular density of $1 \times 10^{7}$ or $5 \times 10^{8} \mathrm{CFU} / \mathrm{ml}$ for soil or seed inoculation, respectively. Tomato plants (cv. Merveille des Marchés) were inoculated, cultivated, and infected with Botrytis cinerea R16 as described by Mariutto and colleagues (2011).

For the induction of ISR with surfactin, tomato seeds were sown in rockwoll and, after germination, were transferred in plastic boxes containing Hoagland hydroponic solution. Three weeks after sowing, plants were treated with $10 \mu \mathrm{M}$ surfactin by adding the elicitor in the hydroponic solution. Three days after induction of resistance, plants were transferred to saturated humidity conditions and were infected as described by Mariutto and collaborators (2011). Infection rates were scored as for the cut tobacco leaves (described above).

\section{Colonization on tomato plantlets.}

Sterilized tomato seeds were pre-germinated for 4 days on solid Hoagland medium ( $26 \mathrm{~g}$ of agar per liter, $\mathrm{pH}$ adjusted to 7) at $28^{\circ} \mathrm{C}$ and $60 \%$ humidity under a 16-h light and 8-h dark circadian cycle. Each seedling was then transferred to an individual petri dish containing a microscope slide covered with Hoagland medium and was incubated under the same conditions. Seven-day-old seedlings were inoculated with $10 \mu \mathrm{l}$ of bacterial suspension. For each strain, this suspension was obtained by centrifuging an overnight culture (Luria medium, $30^{\circ} \mathrm{C}$ ), washing the cells with $10 \mathrm{mM} \mathrm{MgSO}_{4}$, and resuspending them to a density of $1 \times 10^{7} \mathrm{CFU} / \mathrm{ml}$. After inoculation, plantlets were incubated for 2 weeks, after which colonization was evaluated through plate counting and microscopic observation of the biofilm-like structures. These last observations were conducted the day before plate counting, using a light microscope equipped with a $10 \times$ objective. Pictures were taken in black and white mode. For plate counting, results were expressed as CFU per gram of rhizosphere. Plated samples were obtained from total rhizosphere including the plantlet roots, the $2 \mathrm{~mm}$ of agar surrounding them, and all the agar present in between a dense root network.

\section{Assay of LOX activity.}

LOX activity was assayed spectrophotometrically as described by Mariutto and collaborators (2011). Frozen leaf tissue powder was extracted in $100 \mathrm{mM}$ sodium phosphate buffer containing $0.4 \mathrm{~g}$ of $\mathrm{Na}_{2} \mathrm{~S}_{2} \mathrm{O}_{5}$ per liter and $2.5 \mathrm{~g}$ of Tween 20 per liter. After centrifugation $\left(20,000 \times g\right.$ at $4^{\circ} \mathrm{C}$ for $\left.10 \mathrm{~min}\right)$, the supernatant was added to oxygenated $100 \mathrm{mM}$ sodium phosphate buffer, $\mathrm{pH}$ 7.0, and linolenic acid. Enzymatic activity was determined by monitoring the appearance of hydroperoxides at 
$234 \mathrm{~nm}$ with a UVIKON XS spectrophotometer. LOX activity was calculated using an $\varepsilon$ of $25,000 \mathrm{M}^{-1} \mathrm{~cm}^{-1}$ and was expressed in microenzymatic units per gram of fresh weight (mU/g FW).

\section{TomLoxD and TomLoxF genes expression.}

Total mRNA was extracted from frozen leaf tissue powder by the Trizol method according to the protocol recommended by the manufacturer (Gibco BRL, Grand Island, NY, U.S.A.). Analysis of gene expression was done by semiquantitative reverse transcription PCR. First-strand cDNA was synthesized (Smart PCR cDNA synthesis kit; Clontech, Saint-Germain-enLaye, France) according to the manufacturer's instructions. PCR amplifications were performed with the Advantage 2 PCR kit (Clontech). Primers EF1- $\alpha$ f (CTCAAGGATGGACA GACCCG) and EF1- $\alpha$ R (AAGGGGATCTTGTCAGGGTTG) were used to amplify the cDNA of the housekeeping gene elongation factor $1-\alpha(E F 1-\alpha)$, LoxDF (GCACCAGCAGGAG TTCTTTC), and LoxDR (GCTTCTCCACACGACTCTCC) were used to amplify TomLoxD cDNA, and LoxFF (AAGGC ATAACTCAGCTCCA) and LoxFR (TTGGGTAACTTCTGG CCATC) were used to amplify TomLoxF cDNA. PCR reactions contained $1 \mu \mathrm{l}$ of first-strand cDNA and each primer $0.5 \mu \mathrm{M}$. Samples were amplified in a GeneAmp 9700 PCR system (Perkin-Elmer, Norwalk, CT, U.S.A.) as follows: $3 \mathrm{~min}$ at $94^{\circ} \mathrm{C}$; 23 (for EF1- $\alpha$ ) 28 (for TomLoxF), and 29 (forTomLoxD) cycles of $1 \mathrm{~min}$ at $94^{\circ} \mathrm{C}, 1 \mathrm{~min}$ at $58^{\circ} \mathrm{C}$ (for $E F 1-\alpha$ ) or $60^{\circ} \mathrm{C}$ (for TomLoxD and TomLoxF), and $1 \mathrm{~min}$ at $72^{\circ} \mathrm{C} ; 7 \mathrm{~min}$ at $72^{\circ} \mathrm{C}$. PCR products were deposited on gel and after electrophoresis, semiquantitative analysis was conducted by measuring the integrated density values of PCR products in electrophoresis gel pictured with AlphaEaseFC image software (AlphaInnotech, San Leandro, CA, U.S.A.). The band intensities of the genes of interest were normalized with the band intensities of EF1- $\alpha$. Expression levels of TomLoxD and TomLoxF in uninfected control plants was arbitrarily considered as 1 . Relative transcript accumulation was determined by calculating the percentage of difference in normalized band intensities between uninfected controls and each sample. Samples were obtained as for LOX enzyme expression. Data were analyzed using Student's $t$-test $(\alpha=0.05)$.

\section{Quantification of fatty acid hydroperoxides.}

Fatty acid hydroperoxides were extracted from plant tissues, using a method described by Fauconnier and collaborators (2008), with some modifications, and were quantified by UPLC-DAD (ultrahigh pressure liquid chromatography-diode array detector). Powdered frozen leaf tissue $(0.5 \mathrm{~g})$ was extracted in $10 \mathrm{ml}$ of extraction medium (3:2 isohexane/2-propanol (vol/vol), $0.0025 \%$ (wt/vol) butylatedhydroxytoluene). Ricinoleic acid was used as internal standard. After homogenization, the extract was centrifuged at $1,300 \times g$ at $4^{\circ} \mathrm{C}$ for 10 min. The upper phase was collected and added to a $6.7 \%$ (wt/vol) solution of potassium sulfate to reach a volume of 20 $\mathrm{ml}$. After $10 \mathrm{~min}$ of shaking at $4^{\circ} \mathrm{C}$, the extract was centrifuged at $1,300 \times g$ at $4^{\circ} \mathrm{C}$ for $10 \mathrm{~min}$. The upper phase was collected, was dried under nitrogen stream, and was dissolved in hexane. UPLC analysis was carried out on a reverse phase column (Acquity UPLC BEH $1.7 \mu \mathrm{m}, \mathrm{C} 18,2.1 \times 100 \mathrm{~mm}$, Waters), using water, acetonitrile, and phosphate buffer $(\mathrm{pH} 2)$ as solvents in the following gradients: equilibration in 70:20:10 for $5 \mathrm{~min}$ prior to injection; 0 to $6 \mathrm{~min}$, from $70: 20: 10$ to $45: 45: 10$; 6 to $12 \mathrm{~min}, 45: 45: 10 ; 12$ to $20 \mathrm{~min}$, from $45: 45: 10$ to $37: 53: 10$; 20 to $25 \mathrm{~min}, 37: 53: 10 ; 25$ to $29 \mathrm{~min}$, from $37: 53: 10$ to $5: 95: 0$; and 29 to $32 \mathrm{~min}, 0: 100: 0$.. The flow rate was $0.35 \mathrm{ml} / \mathrm{min}$, and compounds were detected at $234 \mathrm{~nm}$. The retention times of the observed fatty acid hydroperoxides were compared with those of commercial 13- and 9-HPOD/HPOT (Larodan). Samples collection and data analysis were conducted as for LOX gene expression.

\section{Analysis of volatiles production.}

Strains were cultivated on solid medium in glass vials. In a first experiment, isolates were grown for $24 \mathrm{~h}$ on a volatile production medium at $36^{\circ} \mathrm{C}$ to place strains in optimized production conditions (Ryu et al. 2004). In a second experiment, strains were cultivated on recomposed exudates medium at $25^{\circ} \mathrm{C}$ for $48 \mathrm{~h}$ to simulate rhizosphere conditions. For inocula preparation, strains were streaked on Luria medium and were incubated overnight at $30^{\circ} \mathrm{C}$. The obtained colonies were scraped off the plates with saline solution ( $9 \mathrm{~g} /$ liter), were centrifuged, and were resuspended to an $\mathrm{OD}_{600 \mathrm{~nm}}=0.5$. A volume of $100 \mu \mathrm{l}$ of inoculum was applied to each vial. After incubation, the headspaces of all cultures were sampled with SPME fibers (with divinylbenzene, carboxen, and polydimethylsiloxane coating of 50 and $30 \mu \mathrm{m} \times 1 \mathrm{~cm}$ ) at $35^{\circ} \mathrm{C}$ for $1 \mathrm{~h}$. Loaded fibers were analyzed with a gas chromatograph (Thermo Fisher Scientific) coupled to a mass spectrometer (Finnigan Trace MS; Thermo Scientific). Desorption was conducted at $225^{\circ} \mathrm{C}$ and injections were conducted in splitless mode. An Optima 5 Accent (Macherey-Nagel, Düren, Switzerland) $30 \mathrm{~m} \times 0.25 \mathrm{~mm}$ ID $0.25 \mu \mathrm{m}$ column was used. Carrier flow was set to $1 \mathrm{ml} / \mathrm{min}$. The oven temperature program was as follows: $40^{\circ} \mathrm{C}$ for $2 \mathrm{~min}$, then a ramp of $5^{\circ} \mathrm{C}$ per minute up to $60^{\circ} \mathrm{C}$, followed by a second ramp of $120^{\circ} \mathrm{C}$ per minute up to $280^{\circ} \mathrm{C}$. This temperature is maintained for $6 \mathrm{~min}$. Scanning range of the MS was set to 35 to 350 . Identification of the acetoin and 2,3-butanediol peaks was based on retention time compared with authentic standards (Sigma-Aldrich, St. Louis) and on MS spectra.

\section{Statistical analysis.}

Data were analyzed by analysis of variance $(P<0.05$, Minitab software). Means from the different treatments were compared using the Newman and Keul's test (least significant difference at $\alpha=0.05$ ).

\section{ACKNOWLEDGMENTS}

This work received financial support from the F.R.F.C. project number 2.4.624.10 of the Belgian National Fund for Scientific Research (FRSF.N.R.S.) and from the INTERREG IV program France-WallonieVlaanderen (Phytobio project). H. Cawoy's and C. Fisher's Ph.D. theses are supported by grants from the Fonds pour la formation à la Recherche dans l'Industrie et dans l'Agriculture (F.R.I.A.). M. Mariutto is Research Fellow and M. Ongena is Research Associate at the F.R.S.-FNRS in Belgium. The authors also thank B. McSpadden Gardener from Ohio State University for providing Bacillus and Paenibacillus strains and also for critically reviewing the manuscript. We also wish to thank V. Pascale, F. Laurent, and S. Pauline for their technical assistance in the realization of this work.

\section{LITERATURE CITED}

Arguelles-Arias, A., Ongena, M., Halimi, B., Lara, Y., Brans, A., Joris, B., and Fickers, P. 2009. Bacillus amyloliquefaciens GA1 as a source of potent antibiotics and other secondary metabolites for biocontrol of plant pathogens. Microb. Cell. Fact. 8:12.

Bais, H. P., Fall, R., and Vivanco, J. M. 2004. Biocontrol of Bacillus subtilis against infection of Arabidopsis roots by Pseudomonas syringae is facilitated by biofilm formation and surfactin production. Plant Physiol. 134:307-319.

Bhattacharyya, P. N., and Jha, D. K. 2012. Plant growth-promoting rhizobacteria (PGPR): Emergence in agriculture. World J. Microbiol. Biotechnol. 28:1327-1350.

Chen, X. H., Koumoutsi, A., Scholz, R., Schneider, K., Vater, J., Sussmuth, R., Piel, J., and Borriss, R. 2009. Genome analysis of Bacillus amyloliquefaciens FZB42 reveals its potential for biocontrol of plant pathogens. J. Biotechnol. 140:27-37.

Choudhary, D. K. 2011. Plant growth-promotion (PGP) activities and mo- 
lecular characterization of rhizobacterial strains isolated from soybean (Glycine $\max$ L. Merril) plants against charcoal rot pathogen, Macrophomina phaseolina. Biotechnol. Lett. 33:2287-2295.

Choudhary, D. K., and Johri, B. N. 2009. Interactions of Bacillus spp., and plants-With special reference to induced systemic resistance (ISR). Microbiol. Res. 164:493-513.

De Meyer, G., and Hofte, M. 1997. Salicylic acid produced by the rhizobacterium Pseudomonas aeruginosa 7NSK2 induces resistance to leaf infection by Botrytis cinerea on bean. Phytopathology 87:588-593

De Vleesschauwer, D., and Höfte, M. 2009. Pages 223-281 in: Rhizobacteria-Induced Systemic Resistance in Advances in Botanical Research, J.-C. Kader, and M. Delseny, eds. Elsevier Ltd, Philadelphia.

Debois, D., Ongena, M., Cawoy, H., and De Pauw, E. 2013. MALDIFTICR MS Imaging as a powerful tool to identify Paenibacillus antibiotics involved in the inhibition of plant pathogens. J. Am. Soc. Mass Spectrom.doi: 10.1007/s13361-013-0620-2, Published online.

Durrant, W. E., and Dong, X. 2004. Systemic acquired resistance. Annu. Rev. Phytopathol. 42:185-209.

Fan, B., Chen, X. H., Budiharjo, A., Bleiss, W., Vater, J., and Borriss, R. 2011. Efficient colonization of plant roots by the plant growth promoting bacterium Bacillus amyloliquefaciens FZB42, engineered to express green fluorescent protein. J. Biotechnol. 151:303-311.

Fauconnier, M. L., Rojas-Beltran, J., Dupuis, B., Delaplace, P., Frettinger, P., Gosset, V., and du Jardin, P. 2008. Changes in oxylipin synthesis after Phytophthora infestans infection of potato leaves do not correlate with resistance. Plant Physiol. Biochem. 46:823-831.

Fraser, C., and Chapple, C. 2011. The phenylpropanoid pathway in Arabidopsis. Page e0152 in: The Arabidopsis Book, R. Last, ed. American Society of Plant Biologists, Danvers, MA, U.S.A. Published online.

García-Gutiérrez, L., Romero, D., Zeriouh, H., Cazorla, F.M., Torés, J. A. de Vicente, A., and Pérez-García, A. 2012. Isolation and selection of plant growth-promoting rhizobacteria as inducers of systemic resistance in melon. Plant Soil 358:201-212.

Hamze, K., Julkowska, D., Autret, S., Hinc, K., Nagorska, K., Sekowska, A., Holland, I. B., and Séror, S.J. 2009. Identification of genes required for different stages of dendritic swarming in Bacillus subtilis, with a novel role for phrC. Microbiology 155:398-412.

Henry, G., Deleu, M., Jourdan, E., Thonart, P., and Ongena, M. 2011. The bacterial lipopeptide surfactin targets the lipid fraction of the plant plasma membrane to trigger immune-related defence responses. Cell. Microbiol. 13:1824-1837.

Henry, G., Thonart, P., and Ongena, M. 2012. PAMPs, MAMPs, DAMPs and others: An update on the diversity of plant immunity elicitors. Biotechnol., Agron., Soc. Environ. 16:257-268.

Hofemeister, J., Conrad, B., Adler, B., Hofemeister, B., Feesche, J., Kucheryava, N., Steinborn, G., Franke, P., Grammel, N., Zwintscher, A., Leenders, F., Hitzeroth, G., and Vater, J. 2004. Genetic analysis of the biosynthesis of non-ribosomal peptide- and polyketide-like antibiotics, iron uptake and biofilm formation by Bacillus subtilis A1/3. Mol. Genet. Genomics 272:363-378.

Jacques, P., Hbid, C., Destain, J., Razafindralambo, H., Paquot, M., De Pauw, E., and Thonart, P. 1999. Optimization of biosurfactant lipopeptide production from Bacillus subtilis $\mathrm{S} 499$ by plackett-burman design. Appl. Biochem. Biotechnol. 77-79:223-233.

Jankiewicz, U., and Kołtonowicz, M. 2012. The involvement of Pseudomonas bacteria in induced systemic resistance in plants (Review). Appl. Biochem. Microbiol. 48:244-249.

Joshi, R., and McSpadden Gardener, B. B. 2006. Identification and characterization of novel genetic markers associated with biological control activities in Bacillus subtilis. Phytopathology 96:145-154.

Jourdan, E., Henry, G., Duby, F., Dommes, J., Barthelemy, J. P., Thonart, P., and Ongena, M. 2009. Insights into the defense-related events occurring in plant cells following perception of surfactin-type lipopeptide from Bacillus subtilis. Mol. Plant-Microbe Interact. 22:456-468.

Kamilova, F., Kravchenko, L. V., Shaposhnikov, A. I., Makarova, N., and Lugtenberg, B. 2006. Effects of the tomato pathogen Fusarium oxysporum f. sp. radicis-lycopersici and of the biocontrol bacterium Pseudomonas fluorescens WCS365 on the composition of organic acids and sugars in tomato root exudate. Mol. Plant-Microbe Interact. 9:1121-1126.

Kinsella, K., Schulthess, C. P., Morris, T. F., and Stuart, J. D. 2009. Rapid quantification of Bacillus subtilis antibiotics in the rhizosphere. Soil Biol. Biochem. 41:374-379.

Kinsinger, R. F., Shirk, M. C., and Fall, R. 2003. Rapid surface motility in Bacillus subtilis is dependent on extracellular surfactin and potassium ion. J. Bacteriol. 185:5627-5631.

López, D., and Kolter, R. 2010. Extracellular signals that define distinct and coexisting cell fates in Bacillus subtilis. FEMS (Fed. Eur. Microbiol. Soc.) Microbiol. Rev. 34:134-149.

López, D., Vlamakis, H., Losick, R., and Kolter, R. 2009. Paracrine signaling in a bacterium. Genes Dev. 23:1631-1638.

Lugtenberg, B., and Kamilova, F. 2009. Plant-growth-promoting rhizobacteria. Ann. Rev. Microbiol. 63:541-556.

Luna, E., Bruce, T. J. A., Roberts, M. R., Flors, V., and Ton, J. 2012. Nextgeneration systemic acquired resistance. Plant Physiol. 158:844-853.

Mariutto, M., Duby, F., Adam, A., Bureau, C., Fauconnier, M. L., Ongena, M., Thonart, P., and Dommes, J. 2011. The elicitation of a systemic resistance by Pseudomonas putida BTP1 in tomato involves the stimulation of two lipoxygenase isoforms. BMC Plant Biol. 11.

McSpadden Gardener, B. B. 2004. Ecology of Bacillus and Paenibacillus spp. in agricultural systems. Phytopathology 94:1252-1258.

Nihorimbere, V., Fickers, P., Thonart, P., and Ongena, M. 2009. Ecological fitness of Bacillus subtilis BGS3 regarding production of the surfactin lipopeptide in the rhizosphere. Environ. Microbiol. Rep. 1:124-130.

Nihorimbere, V., Cawoy, H., Seyer, A., Brunelle, A., Thonart, P., and Ongena, M. 2012. Impact of rhizosphere factors on cyclic lipopeptide signature from the plant beneficial strain Bacillus amyloliquefaciens S499. FEMS (Fed. Eur. Microbiol. Soc.) Microbiol. Ecol. 79:176-191.

Ongena, M., and Jacques, P. 2008. Bacillus lipopeptides: Versatile weapons for plant disease biocontrol. Trends Microbiol. 16:115-125.

Ongena, M., Duby, F., Rossignol, F., Fauconnier, M. L., Dommes, J., and Thonart, P. 2004. Stimulation of the lipoxygenase pathway is associated with systemic resistance induced in bean by a nonpathogenic Pseudomonas strain. Mol. Plant-Microbe Interact. 17:1009-1018.

Ongena, M., Duby, F., Jourdan, E., Beaudry, T., Jadin, V., Dommes, J., and Thonart, P. 2005a. Bacillus subtilis M4 decreases plant susceptibility towards fungal pathogens by increasing host resistance associated with differential gene expression. Appl. Microbiol. Biotechnol. 67:692-698.

Ongena, M., Jacques, P., Touré, Y., Destain, J., Jabrane, A., and Thonart, P. 2005b. Involvement of fengycin-type lipopeptides in the multifaceted biocontrol potential of Bacillus subtilis. Appl. Microbiol. Biotechnol. 69:29-38.

Ongena, M., Adam, A., Jourdan, E., Paquot, M., Brans, A., Joris, B., Arpigny, J. L., and Thonart, P. 2007. Surfactin and fengycin lipopeptides of Bacillus subtilis as elicitors of induced systemic resistance in plants. Environ. Microbiol. 9:1084-1090.

Prost, I., Dhondt, S., Rothe, G., Vicente, J., Rodriguez, M. J., Kift, N., Carbonne, F., Griffiths, G., Esquerré-Tugayé, M. T., Rosahl, S., Castresana, C., Hamberg, M., and Fournier, J. 2005. Evaluation of the antimicrobial activities of plant oxylipins supports their involvement in defense against pathogens. Plant Physiol. 139:1902-1913.

Raaijmakers, J. M., de Bruijn, I., Nybroe, O., and Ongena, M. 2010. Natural functions of lipopeptides from Bacillus and Pseudomonas: More than surfactants and antibiotics. FEMS (Fed. Eur. Microbiol. Soc.) Microbiol Rev 34:1037-1062.

Ramey, B. E., Koutsoudis, M., von Bodman, S. B., and Fuqua, C. 2004. Biofilm formation in plant-microbe associations. Curr. Opin. Microbiol. 7:602-609.

Rückert, C., Blom, J., Chen, X., Reva, O., and Borriss, R. 2011. Genome sequence of $B$. amyloliquefaciens type strain DSM7T reveals differences to plant-associated B. amyloliquefaciens FZB42. J. Biotechnol. 155:78-85.

Ryu, C. M., Farag, M. A., Hu, C. H., Reddy, M. S., Kloepper, J. W., and Pare, P. W. 2004. Bacterial volatiles induce systemic resistance in Arabidopsis. Plant Physiol. 134:1017-1026.

Shah, J. 2005. Lipids, lipases, and lipid-modifying enzymes in plant disease resistance. Ann. Rev. Phytopathol. 43:229-260.

Shah, J. 2009. Plants under attack: Systemic signals in defence. Curr. Opin. Plant Biol. 12:459-464.

Stein, T. 2005. Bacillus subtilis antibiotics: Structures, synhesis and specifics functions. Mol Microbiol 56:845-847.

van den Burg, H. A., and Takken, F. L. W. 2009. Does chromatin remodeling mark systemic acquired resistance? Trends Plant Sci. 14:286-294.

Van Loon, L. C. 2007. Plant responses to plant growth-promoting rhizobacteria. Eur. J. Plant Pathol. 119:243-254.

Vanitha, S. C., and Umesha, S. 2011. Pseudomonas fluorescens mediated systemic resistance in tomato is driven through an elevated synthesis of defense enzymes. Biol. Plant. 55:317-322.

Yang, S. Y., Park, M. R., Kim, I. S., Kim, Y. C., Yang, J. W., and Ryu, C. M. 2011. 2-Aminobenzoic acid of Bacillus sp. BS107 as an ISR determinant against Pectobacterium carotovorum subsp. carotovotrum SCC in tobacco. Eur. J. Plant Pathol. 129:371-378. 